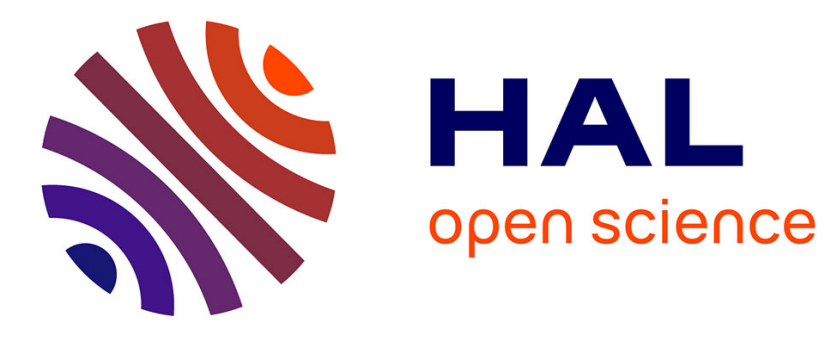

\title{
Quantifying magma segregation in dykes
}

Philippe Yamato, Thibault Duretz, D.A. May, Romain Tartese

\section{To cite this version:}

Philippe Yamato, Thibault Duretz, D.A. May, Romain Tartese. Quantifying magma segregation in dykes. Tectonophysics, 2015, 660, pp.132-147. 10.1016/j.tecto.2015.08.030 . insu-01191513

\section{HAL Id: insu-01191513 https://hal-insu.archives-ouvertes.fr/insu-01191513}

Submitted on 2 Sep 2015

HAL is a multi-disciplinary open access archive for the deposit and dissemination of scientific research documents, whether they are published or not. The documents may come from teaching and research institutions in France or abroad, or from public or private research centers.
L'archive ouverte pluridisciplinaire HAL, est destinée au dépôt et à la diffusion de documents scientifiques de niveau recherche, publiés ou non, émanant des établissements d'enseignement et de recherche français ou étrangers, des laboratoires publics ou privés. 


\title{
Quantifying magma segregation in dykes
}

\author{
Yamato P., 2,* ${ }^{1,}$ Duretz T. ${ }^{3}$, May D.A. ${ }^{2}$ and Tartèse R. ${ }^{4,5}$
}

${ }^{1}$ Géosciences Rennes, CNRS UMR 6118, Université de Rennes 1, 35042 Rennes Cedex, France

${ }^{2}$ Institute of Geophysics, ETH Zürich, Sonneggstrasse 5, CH-8092 Zürich, Switzerland

${ }^{3}$ Institute of Geology and Palaeontology, University of Lausanne, CH-1015 Lausanne, Switzerland

${ }^{4}$ Institut de Minéralogie, de Physique des Matériaux et de Cosmochimie, Muséum National

d'Histoire Naturelle, Sorbonne Universités, CNRS, UMPC \& IRD, 75005 Paris, France

${ }^{5}$ Planetary and Space Sciences, The Open University, Walton Hall, Milton Keynes, MK7 6AA,

United Kingdom

*Corresponding author: philippe.yamato@univ-rennes1.fr

Submission to: Tectonophysics 


\section{Abstract}

The dynamics of magma flow is highly affected by the presence of a crystalline load. During magma ascent, it has been demonstrated that crystal-melt segregation constitutes a viable mechanism for magmatic differentiation. Moreover, crystal-melt segregation during magma transport has important implications in term of magma rheology, but also in term of differentiation of the continental crust. However, the influences of the crystal volume percentage $(\varphi)$, of their geometry, their size and their density on crystal-melt segregation are still not well constrained. To address these issues, we performed a parametric study using $2 \mathrm{D}$ direct numerical simulations, which model the ascension of a crystal-bearing magma in a vertical dyke. Using these models, we have characterised the amount of segregation as a function of different physical properties including $\varphi$, the density contrast between crystals and the melt phase $(\Delta \rho)$, the size of the crystals $\left(A_{c}\right)$ and their aspect ratio $(R)$. Results show that small values of $R$ do not affect the segregation. In this case, the amount of segregation depends upon four parameters. Segregation is highest when $\Delta \rho$ and $A_{c}$ are large, and lowest for large pressure gradient $\left(P_{d}\right)$ and/or large values of dyke width $\left(W_{d}\right)$. These four parameters can be combined into a single one, the $S_{\text {number }}$, which can be used to quantify the amount of segregation occurring during magma ascent. Based on systematic numerical modelling and dimensional analysis, we provide a first order scaling law which allows quantification of the segregation for an arbitrary $S_{\text {number }}$ and $\varphi$, encompassing a wide range of typical parameters encountered in terrestrial magmatic systems. Although developed in a simplified system, this study has strong implications regarding our understanding of crystal segregation processes during magma transport. Our first order scaling law allows to immediately determine the amount of crystal-melt segregation occurring in any given magmatic dyke system.

Keywords: Segregation; Differentiation; Dykes; Magma dynamics; Numerical modelling 


\section{Introduction}

\subsection{Background}

Magmatic differentiation constitutes one of the major mechanisms that shapes internal structures and governs the chemical composition of various reservoirs in planetary bodies. The terrestrial continental crust, for instance, grew and differentiated through magmatism. Its present-day structure implies a two-stage process including extraction of basaltic magmas sensu lato from the mantle followed by their differentiation and new partial melting events within the crust, leading to the formation of a more evolved, granitic sensu lato, upper crust (e.g., Taylor and McLennan, 1995; Hawkesworth and Kemp, 2006). Amongst the processes governing the upward travel of magma through the mid- to upper continental crust, dyking constitutes a key mechanism (e.g. Nicolas, 1986; Clemens and Mawer, 1992; Petford et al., 2000; Vigneresse and Clemens, 2000). Therefore, it appears that upward magma transport in dykes through the crust inherently promotes magmatic differentiation. Unfortunately, it is not possible to directly observe such processes occurring at depth. Instead, mineralogical and geochemical observations are used to identify suites of cogenetic rocks, somehow related to each other, and which provide snapshots of different stages of magmatic differentiation. These observations of mineralogical and geochemical differentiation trends in rock suites ranging from basaltic to granitic compositions have often been explained by fractionation of crystals, at depth, in ascending magmas (e.g. Philpotts et al, 1998; Tartèse and Boulvais, 2010; Fourmentraux et al., 2012; Morfin et al., 2014; Ballouard et al., 2015).

Nevertheless, the underlying physical mechanisms inducing magmatic differentiation during magma ascent remains unclear (e.g. Marsh, 2013). Thorough experimental studies have investigated the effects of the different physical processes involved during flowing of magmatic mushes, such as diapiric percolation or sedimentation of heavy particles, buoyancy-driven compaction, melt filtering 
in response to differential stresses (e.g., Bagdassarov et al., 1996a; 1996b; Bagdassarov and Dorfman, 1998) or gas-driven filter pressing (Sisson and Bacon, 1999). To date, quantitative studies of processes, such as crystal-melt segregation during magma ascent in dykes, have not been carried out. In a previous numerical study, Yamato et al. (2012) argued that crystal-melt segregation in dykes seems to be viable for viscous granitic systems under specific conditions, but further investigations are required to precisely quantify the effects of the different physical parameters at play. Whilst the impact of the abundance or the shape of crystals on the effective viscosity of the magmatic mushes have been intensively addressed (e.g., Costa et al., 2009, and references therein), their impact on the amount of crystal-melt segregation itself, especially in the case of magma flowing within a dyke, has not yet been comprehensively investigated. This study therefore aims to fill this gap and proposes to characterise the amount of segregation through a series of twodimensional numerical experiments.

\subsection{Crystal-melt segregation processes}

Mechanical segregation refers to the process by which melt can separate from the surrounding crystals in a magma. Processes inducing segregation in emplaced magmatic intrusions and deforming partially molten aggregates have been extensively studied (e.g. McKenzie, 1984; Fountain et al., 1989; Brown et al. 1995; Vigneresse et al., 1996; Rabinowicz and Vigneresse, 2004; Katz et al., 2006; Suckale et al., 2012a, 2012b). In dykes, segregation may also occur when the rising magma carries a negatively buoyant crystalline load (Yamato et al., 2012), or when obstacles affect the flow (e.g. wall roughness). The amount of segregation is considered equal to zero if the crystal volume percentage $\varphi$ does not change during magma ascent (i.e. the composition of the magma is not modified during its ascent). Conversely $100 \%$ of segregation corresponds to the cases where the melt phase only is extracted from the mush upward leading to a complete separation between the entire crystalline load and the melt (constituting, by the way, the essential idea of fractional crystallisation; Bowen, 1928). The primary aim of this study is to constrain the physical 
conditions allowing for crystal-melt segregation during magma ascent in a dyke. The mechanism by which segregation occurs in dyke will be discussed in detail within Section 4. Various mechanisms have been invoked to explain crystal-melt segregation in magmas, such as compaction and filterpressing (e.g., see Bagdassarov et al., 1996a, Bagdassarov and Dorfman, 1998). These studies have investigated the physical conditions promoting either compaction or filter-pressing. Irrespective of the type of segregation mechanism, the aim of this study is to be able to (i) predict whether segregation will occur for a given system and (ii) quantify the amount of crystal-melt segregation.

\subsection{Two-phase flow regimes}

Magmas are multiphase systems, containing crystals, gas bubbles and silicic melt in different volumetric proportions. However, we do not considered here the possible effects of gas bubbles, since during magma transport at depth in the continental crust, magmatic volatiles are dissolved in the melt phase (e.g., Zhang et al., 2007). We thus consider magmas as two-phase systems composed of solid crystals suspended in a melt phase below the maximum packing fraction (Saar and Manga, 2002). The dynamics of such systems is highly dependent on the volume fraction occupied by each phase (e.g., Costa et al., 2009) and on the viscosity of the carrier fluid. In the context of Stokes fluids, which we consider here (i.e. rigid crystal suspended in magmatic melt), we summarise three different two-phase flow regimes. A dilute flow is one in which the volume percentage of the solid phase $(\varphi)$ is small (i.e., crystallinity lower than $\sim 1 \%$ ) and the particle motion is purely determined by the fluid motion, which give rise to surface and body forces acting on each particle (one-way coupled). With increasing volume fraction of the solid phase (i.e., crystallinity from $\sim 1 \%$ to $30 \%$ ), feedbacks between the motion of the solids and the fluid occur due to hydrodynamical interactions (two-way coupled). When $\varphi$ is higher than $\sim 30 \%$, dense flow ensues in which particle interactions (e.g. collisions) provide the dominant mechanism in defining the particle motion (four-way coupled - i.e. implying solid-solid, fluid-solid, solid-fluid, fluid-fluid interactions). 
We note that a diverse range of numerical methods have been developed to study the dynamics of dispersed two-phase systems - however the "method of choice" is strongly related to the flow regime of interest (see Prosperetti and Tryggvason (2007) for an overview of the modelling approaches). To understand segregation processes within dykes, we are primarily concerned by the systems undergoing a transition from being two-way coupled to being four-way coupled. In this context, the four-way coupled end-member would represent the deformation of a partially molten rock possessing a small fraction of melt. In such a situation, the deformation of the solid phase dominates the deformation of the melt. This end member can be efficiently modelled using a "twofluid" or "two-phase" model where volume averaged properties of the solid and melt phase are represented and evolved through time (McKenzie, 1985; Scott and Stevenson, 1986; Dufek and Bergantz, 2005; Keller et al., 2013). Two-phase models do not explicitly represent the finite size and geometry of individual solids. Consequently, such methods cannot be used to accurately model the dynamics of two-way coupled systems which require resolving the hydrodynamical interactions and coupling between the fluid motion and particle motion.

\subsection{Motivation of this study}

In this paper, we present two-dimensional (2D) numerical models of crystal-bearing magmas ascending in a vertical conduit simulating a dyke. We quantify the amount of crystal-melt segregation and its dependency on magma properties (i.e., its crystal volume percentage, the density contrast between crystals and melt, the size of the crystals and their aspect ratio) through a parametric study. Based on the results obtained from this systematic study, we develop a scaling law that allows predicting the amount of segregation as a function of (i) the physical characteristics of the magmatic system and of (ii) parameters governing its ascent in a vertical dyke. This study is focused on the segregation of crystals presenting the same size, typical for monodisperse suspensions, within a dyke subject to a pressure gradient across a vertical column. The models have been designed to simulate ascending magma involving crystals initially present in the melt and 
directly apply to granitic dykes systems developing at depth in the crust as it has been proposed that magmatic differentiation during magma transport could occur in such systems, based on petrological and geochemical considerations (e.g., Tartèse and Boulvais, 2010; Morfin et al., 2014; Ballouard et al., 2015). Nevertheless, the results can be generalised to more mafic systems where physical parameters (i.e., density contrast between crystals and melt, crystal abundance, pressure gradient, etc.) remain similar (assuming that other processes such as thermal dependency or volatile exsolution of a gas phase does not come into play). Since such a study on magma ascending in a dyke has never been carried out before, it provides important results for our understanding of crystal-melt segregation processes. In addition, we also provide in the discussion a comparison with previous studies that have addressed questions related to segregation processes in different contexts and discuss the limitations of our model.

\section{Methods}

\subsection{Numerical Model}

To study segregation processes within ascending crystal-bearing magma columns, we use in this work a 2D direct numerical simulation (DNS) methodology. We consider the dynamics of the multi-phase flow to be governed via incompressible Stokes flow (Yamato et al., 2012). In our DNS formulation, we explicitly represent finite sized, arbitrary shape crystals as prismatic inclusions with viscosity $\eta_{c}$ and density $\rho_{c}$. The melt phase is described as a low viscosity fluid, $\eta_{m}<<\eta_{c}$, with density $\rho_{m}<\rho_{c}$. We consider non-deforming crystals - i.e. the activation energies between the suspending melt and the crystals are not comparable, thus implying that the deformation is totally accounted for by the melt phase (e.g. Caricchi et al., 2008). For this, we enforce that the strain-rate tensor within each crystal domain vanishes by defining a crystalline viscosity of $\eta_{c}=10^{6} \eta_{m}$, thereby effectively ensuring each crystal behaves as a rigid body (see Fig. A3 in Appendix). Hence, in a 
frame of reference moving with the fluid velocity, $\eta_{m}, \eta_{c}, \rho_{m}$ and $\rho_{c}$ remain constant (i.e., $\frac{D \rho_{i}}{D t}=0$;

$\frac{D \eta_{i}}{D t}=0$, with $i=m$ or $c$ for the melt or the crystal, respectively).

Our numerical code solves, in two dimensions, the Stokes equations (Eqs. 1 and 2), subject to the incompressibility constraint (Eq. 3):

$$
\begin{aligned}
& -\frac{\partial P}{\partial x}+\frac{\partial \sigma_{x x}}{\partial x}+\frac{\partial \sigma_{x z}}{\partial z}=0 \\
& -\frac{\partial P}{\partial z}+\frac{\partial \sigma_{z z}}{\partial z}+\frac{\partial \sigma_{z x}}{\partial x}=\rho g \\
& \frac{\partial U x}{\partial x}+\frac{\partial U z}{\partial z}=0
\end{aligned}
$$

where $P, \sigma_{i j}, \rho$, and $g$ are the pressure, the deviatoric stress tensor, the density, and the gravitational acceleration, respectively. $U x$ and $U z$ are the two components of the velocity vector in $2 \mathrm{D}(x, z)$ Cartesian coordinate system. These equations are discretised over a rectangular model domain using a finite difference staggered grid. The spatial discretisation of the material properties (viscosity and density) are provided via Lagrangian markers (Gerya and Yuen, 2003). No distinction is made between the markers used to define the crystals and the melt, other than in the definition of their material properties (i.e., viscosity and density). At each time step, material properties defined on the markers are interpolated to the nodes in the finite difference mesh using a distance-dependent interpolation (1-Cell) to solve the Stokes problem (Eqs. 1, 2 and 3). All markers are then evolved forward in time using a $4^{\text {th }}$ order (in space) Runge-Kutta scheme. In our formulation, no special treatment is required to deal with crystal collisions. Since we model the fluid flow outside and inside crystals, and both fluid regions are incompressible, inter-penetration of crystals cannot occur. However, due to temporal errors associated with the time integrator, particles may become close (i.e., separated by less than the size of one control volume length). In this case, the projection method used to map marker viscosities to cell viscosities may result in the apparent connection of two crystals. 
Further details concerning the accuracy of this method for fluid-solid interactions are available in

Duretz et al. (2011) and Yamato et al. (2012). Particularly, readers can refer to Yamato et al. (2012, section 3) for the convergence tests showing the evolution of the discretisation errors for both the velocity and the pressure. Moreover, the only differences between the numerical code used in this study and the one used in Yamato et al. (2012) are (i) the implementation of inertia and (ii) the usage of an OpenMP parallel sparse direct solver, PARDISO (Schenk and Gärtner, 2004), employing LU factorisation. Verification test concerning the implementation of inertia is presented in Appendix A1. Simulations of the reference experiment performed using 1, 2, 4, 8 and 16 threads yielded similar results.

\subsection{Model description}

The model domain is defined as a $1 \mathrm{~m}$ wide $(W)$ and $7.75 \mathrm{~m}$ high $(L)$ box (Fig. 1a). The bottom of the domain consists of a $2.5 \mathrm{~m}$ high magma reservoir constituted by both crystal and melt. A vertical conduit with a width of $0.5 \mathrm{~m}\left(W_{d}\right)$ and a height of $5 \mathrm{~m}\left(L_{d}\right)$ representing the dyke is directly located above the reservoir. Rigid blocks are located on both sides of the conduit and an additional crystal-free reservoir is located above the dyke. The positions of the crystals within the reservoir are randomly generated. Such approach allows producing initial crystal configurations for different initial crystal volume percentage $(\varphi$, up to $45 \%)$, size $\left(A_{c}\right)$, or aspect ratio $(R)$. The melt viscosity $\left(\eta_{m}\right)$ is set to $10^{4} \mathrm{~Pa}$.s, which is a typical value for a granitic melt around $800{ }^{\circ} \mathrm{C}$ containing $4-5$ wt.\% $\mathrm{H}_{2} \mathrm{O}$ (Scaillet et al., 1996; Clemens and Petford, 1999), whereas the crystals are considered as rigid $\left(\eta_{c}=10^{10} \mathrm{~Pa} . \mathrm{s}\right)$. The density of the melt $\left(\rho_{m}\right)$ is set to $2400 \mathrm{~kg} \cdot \mathrm{m}^{-3}$, which is also typical of melts with granitic compositions (e.g., Knoche et al., 1995), whereas the density of the crystals $\left(\rho_{c}\right)$ constitutes one of the parameter investigated in this study. Both the negative buoyancy of crystals and the applied pressure gradient are responsible for driving the flow within the model domain. The negative buoyancy force is generated by the density difference between the solid and melt phases

$(\Delta \rho)$. The pressure gradient $\left(P_{d}\right)$ results from the motion of the rigid blocks $\left(\eta_{b}=10^{11}\right.$ Pa.s) located 
on each lateral side of the dyke and indenting the magmatic mush with a constant velocity $U_{z}$ defined as:

$$
U_{z}=-\frac{P_{d} W_{d}{ }^{2}}{24 \eta_{m}} .
$$

The value of the imposed pressure gradient therefore corresponds to the pressure gradient obtained in the crystal-free case (see Appendix A in Yamato et al., 2012). In our simulations, a pressure gradient of $24 \mathrm{~Pa}^{-1}$ is used. This value ensures the onset of segregation for the considered experimental conditions (Yamato et al., 2012). A grid resolution of 401 by 1551 nodes (i.e. producing a spatial resolution of $\Delta x=2.5 \mathrm{~mm}$ and $\Delta z=5 \mathrm{~mm}$ ) was used for the numerical calculations (resolution tests performed in Yamato et al. (2012) have shown that this resolution is sufficient to resolve the essential features of the crystalline flow), and $\sim 5000$ to 20000 time steps were usually performed during each simulation. Boundary conditions are set to free slip on all sides except along the rigid blocks where $U_{x}=0$ and $U_{z}$ is imposed following the Eq. 4 . The numerical simulations were carried out under the acceleration of gravity $\left(g=10 \mathrm{~m} \cdot \mathrm{s}^{-2}\right)$. In the following, we will investigate the effect of the crystal volume percentage, density, size, and aspect ratio on the process of mechanical segregation of crystals from the melt during magma ascent in dyke.

Contrary to natural systems, the scenario modelled in this study uses an idealised geometry. It does not take into account any complexity of the dyke structure (e.g., rough edges, obstacles affecting segregation processes). Moreover, the applied pressure gradient is controlled (and constant), which is ensured by the rectangular transition geometry between the reservoir and the dyke. This also implies that fracturing processes leading to dyke formation are not investigated here. For this study, we, therefore, consider such approach as valid, limiting the number of parameters investigated to those related to the magmatic mush itself (i.e., crystal volume percentage $\varphi$, crystal-melt density contrast $\Delta \rho$, crystal size $A_{c}$ and their aspect ratio $R$ ). Our model also ignores some additional 
parameters, such as temperature or the effect of chemical processes (e.g., melt crystallisation, gas exsolution, etc.). These parameters are obviously important in terms of volcanic processes and magma dynamics (e.g., Dingwell, 1998; Manga et al., 1998; Turcotte and Schubert, 2002), and could promote the formation of some of the textures that have been described in dykes, such as chilled margins (Huppert and Sparks, 1989) or local concentrations of crystals toward the centre of dykes (e.g., Bagnold, 1954; Barrière, 1976). However, we consider them as negligible in this study focusing on the ascent of granitic-like magma at depth in the crust, where gas phase has not yet been exsolved from the melt since volatiles are dissolved in it (e.g., Zhang et al., 2007) and where mechanical advection of particles is orders of magnitude faster $\left(\sim 10^{-5} \mathrm{~m} . \mathrm{s}^{-1}\right.$ here $)$ compared to the rate over which chemical diffusion, and hence crystal growth, would operate (chemical diffusion of alkalis, for example, such as $\mathrm{Li}, \mathrm{Na}$ or $\mathrm{K}$ typically occurs at rates of $\sim 10^{-10}$ to $10^{-12} \mathrm{~m}^{2} \cdot \mathrm{s}^{-1}$ at $700-800$ ${ }^{\circ} \mathrm{C}$ in rhyolitic melts; Zhang et al., 2010).

\section{Results}

\subsection{Reference model}

In the reference model, the magma reservoir initially contains a crystal volume percentage $\varphi$ of $15 \%$ (200 crystals) randomly distributed in space. The density difference between the crystals and the melt $\Delta \rho$ is set to $300 \mathrm{~kg} \cdot \mathrm{m}^{-3}$ (i.e. $\rho_{c}=2700 \mathrm{~kg} \cdot \mathrm{m}^{-3}$ ). Each crystal has an area $\left(A_{c}\right)$ of $0.025 \times 0.075$ $\mathrm{m}^{2}$ and an aspect ratio $R$ of 3 , corresponding to the ratio between its long and short axis. Compression of the reservoir due to the downward motion of the rigid blocks induces flow within the dyke conduit (Fig. 1b). However, as the crystals are denser than the melt $(\Delta \rho>0)$, convection may occur during the magma ascent leading to the extraction of the liquid phase above the crystals. This type of mechanical segregation results from the competition between the pressure driving the flow through the conduit and the negative buoyancy of the crystalline load, which acts in the opposite direction. Again, these parameters have been selected for the reference model in order to 
simulate ascent in a dyke of a typical granitic magma, constituted by a melt with a viscosity of $\sim 10^{4}$ Pa.s (e.g., Clemens, 1998; Scaillet et al., 1996; Clemens and Petford, 1999) and a density of 2400 kg.m ${ }^{-3}$ (Knoche et al., 1995), and crystals (such as plagioclase and K-feldspars, with densities of 2600-2800 kg.m ${ }^{-3}$ ) therefore characterised by a density difference $\Delta \rho$ relative to the melt in the range of $200-400 \mathrm{~kg} \cdot \mathrm{m}^{-3}$. The crystal dimensions used in the reference model may appear large. However, such crystal sizes are commonly observed in granites in nature (e.g., Vernon, 1986; Solgadi and Sawyer, 2008; Vernon and Paterson, 2008, Barboni and Schoene, 2014). The advantage of using large crystals in the reference model is to ensure that they are sufficiently resolved by our computational grid. Moreover, results from this reference setup can be easily rescaled. Hence, for example, the results obtained, in terms of physical process, will be similar considering a crystal twice smaller in length (i.e., four times smaller in terms of surface area $A_{c}$ ) evolving in a dyke twice thinner if time and pressure gradient are also scaled accordingly (see Yamato et al., 2012). Finally, since the size of the crystals, their density, and their aspect ratio constitute parameters tested through our parametric study, the choice of arbitrary lengths, density and aspect ratios for the reference experiment is not crucial, their respective influences being discussed in detail in Section 3.3.

\subsection{Segregation definition}

In this study, we define the amount of crystal-melt segregation from the magma as follows:

$$
\operatorname{Seg}=\frac{V_{m}-V_{t}}{V-V_{t}},
$$

where $V$ and $V_{m}$ correspond to the total volume of material (crystal and melt) and to the volume of melt only located within the dyke (i.e. material above the base of the rigid blocks, see Fig. 2 for illustration), respectively (and $V=V_{m}+V_{c}$, see Fig. 2). $V_{t}$ corresponds to the theoretical volume of 
melt that would be obtained considering no segregation and can be calculated for any crystal fraction $(\varphi)$ as:

$$
V_{t}=V(1-\varphi)
$$

$V$ can be also obtained through time $t$, analytically, by considering a crystal-free case (Fig. 2a) and using the following equation (See Appendix in Yamato et al., 2012 for further details):

$$
V=\frac{2 P_{d} W_{d}^{3} t}{24 \eta_{m}}
$$

Segregation $(\mathrm{Seg})$ in the model can therefore be computed from the volume of melt measured within the dyke. Fig. $2 \mathrm{c}$ shows the evolution of $V, V_{m}$, and $V_{t}$ for the reference model through time. The corresponding segregation values are plotted in Fig. 2d. This figure shows that crystal-melt segregation stabilises after an initial transient stage. Values of segregation for each time-step between $20000 \mathrm{~s}$ and $40000 \mathrm{~s}$ were integrated over time to ensure that they are representative of steady-state segregation for each model. This also permits to avoid any possible perturbation, caused, for example, by injection of a large volume of material, originally resting at the bottom of the reservoir, which then locally contains a higher crystal fraction. Segregation thus refers to a segregation amount, in contrast with the segregation rate (volume of extracted melt with time), which in our case (between $20000 \mathrm{~s}$ and $40000 \mathrm{~s}$ ) is almost constant in time.

\subsection{Parametric study}

\subsubsection{Initial crystal arrangement}


To study the impact of the initial crystal arrangement in our simulations, we ran two end-member series of simulations with crystals initially oriented either horizontally or vertically (Fig. 3a). Results after $40000 \mathrm{~s}$ of the numerical simulation are presented in Fig. $3 \mathrm{~b}$ for a volume percentage $\varphi$ of crystal of $15 \%$. Altogether, these results show that the initial arrangement of the crystals in the magma has a limited impact on the flow dynamics inside the conduit. Fig. 3c illustrates the dependency of the amount of segregation in the dyke to the initial crystal fraction for vertically-, horizontally- and randomly- distributed crystals where only small fluctuations were obtained over the crystallinity range. This shows that small variations in the segregation values are observed between $\varphi=15 \%$ and $\varphi=30 \%$, but they never exceeded $\pm 10 \%$. The initial crystal arrangement, therefore, does not influence whether segregation will occur or not.

\subsubsection{Crystal aspect ratio}

Previous studies focused on magma rheology have shown that crystal aspect ratio plays an important role on the effective magma viscosity (e.g. Mueller et al., 2010; 2011; Cimarelli et al., 2011; Picard et al., 2013). In order to study the impact of crystal aspect ratio $R$ on the segregation, we designed several numerical experiments in which $R$ varies while keeping the crystal areas $A_{c}$ fixed (which ensure a constant mass for the crystals). Results for $\varphi=15 \%$ are presented in Fig. 4 for $R=1,2,3,4,5$ and $10 . R$ can affect the behaviour of the magma within the dyke (hence the segregation) when the long axis $\left(L_{c}\right)$ of the crystals is larger than $\sim 1 / 6$ of the dyke width. In the other numerical simulations $\left(L_{c}<1 / 6 W_{d}\right)$, the effect of $R$ on the amount of segregation process appears insignificant (Fig. 4). Thereafter, we will consider this last case, which appears to be the most frequent in nature, even though we are well aware that in extreme case $\left(L_{c}>1 / 6 W_{d}\right), R$ will play a primary role. Indeed, if crystals are of similar size as the conduit, it will impede flow significantly.

\subsubsection{Crystal volume percentage}


Crystal fraction constitutes one of the most influential parameters on the behaviour of magmas (e.g. Vigneresse et al., 1996; Caricchi et al., 2007). Numerical experiments have been carried out for $\varphi$ varying from 5\% (67 crystals) to $\varphi=45 \%$ (600 crystals). The results obtained after $40000 \mathrm{~s}$ of the simulation are presented in Fig. 5. They show that increasing the crystal fraction dramatically influences the magma behaviour in the dyke. When the crystal fraction increases, magma flow evolves from a typical Poiseuille-type, to an apparent Bingham-like flow (i.e., exhibiting a plugflow velocity profile), in agreement with previous studies (e.g. Petford and Koenders, 1998; Petford, 2003; Yamato et al., 2012). This transition takes place for $\varphi>15-35 \%$ and corresponds to the transition between $\sim 90 \%$ and $\sim 10 \%$ of segregation (Fig. 3c). Segregation amount decreases with increasing $\varphi$ and follows a cumulative normal distribution law (Fig. 3c). At high crystal volume percentage (Fig. 5 at $\varphi=35 \%$ and $45 \%$ ), in dense flows, melt extraction occurs differently. When the average crystal spacing is small, melt extraction (and hence segregation) is hindered. The liquid phase is collected in "melt pockets" located between crystal aggregates. The growth of melt pockets causes melt depletion and thus crystal aggregation in adjacent regions. The extraction of melt pockets may occur once their buoyancy overcomes the resistance of the surrounding crystalline mush. As a result, extraction of pockets occurs in pulses causing transient variations of the segregation.

\subsubsection{Crystal-melt density difference}

As segregation results from the competing effects of negative crystal buoyancy and upward pressure gradient, the effect of the crystal-melt density difference $(\Delta \rho)$ naturally controls the amount of segregation. Fig. 6a shows how small variations of $\Delta \rho$ dramatically influence the segregation amount: the higher the density contrast, the larger the segregation. Fig. $6 \mathrm{~b}$ illustrates how the cumulative normal distribution of segregation (which is a function of $\varphi$, see Section 3.3.3. above) changes with the crystal-melt density difference. When $\Delta \rho$ increases, the mean of the cumulative 
normal distribution (i.e. the volume percentage of crystals $\varphi$ needed to obtain $50 \%$ of segregation) increases and the standard deviation of this curve decreases (i.e. the slope of the curve increase). This means that the transition from $100 \%$ to $0 \%$ of segregation occurs for a smaller range of $\varphi$ with increasing $\Delta \rho$.

\subsubsection{Crystal size}

The crystalline load affects the segregation process; however the numerical experiments described above only consider a fixed total volume of crystals (at a given $\varphi$ ) and do not investigate the impact of the mass of each crystal (for a fixed $\Delta \rho$ ). We performed several experiments considering the same crystal fraction but changing the size of each crystal (i.e., the surface area $A_{c}$, in $2 \mathrm{D}$ ) while ensuring a fixed total crystalline mass. The results show that larger crystals result in a higher amount of segregation for a fixed $\varphi$ (Fig. 7). The impact on the crystal-melt segregation process is drastic. For a crystal volume percentage $\varphi$ of $15 \%$ for example, reducing the crystal size by a factor of 4 resulted in a decrease of the percentage of segregation from $85.6 \%$ to $17.3 \%$. In contrast, increasing the crystal size by a factor of 4 resulted in their complete segregation from the melt $(100 \%)$. The crystal size thus constitutes an important parameter controlling the amount of segregation.

\subsection{First order scaling for predicting the amount of segregation}

As presented above, the dominant parameters which control magma segregation during magma ascent are (1) the crystal-melt density difference, (2) the crystal size, (3) the initial fraction of crystal in the reservoir, and (4) the applied pressure gradient (Yamato et al, 2012). In order to combine these parameters, we propose a non-dimensional number, the $S_{\text {number }}$, expressed as: 


$$
S_{\text {number }}=\frac{\Delta \rho g A_{c}}{P_{d} W_{d}^{2}}
$$

This number does not directly correspond to the segregation amount because the crystal fraction is not included; however the $S_{\text {number }}$ is suitable to describe the flow behaviour observed in the different numerical simulations. Indeed, for a given crystal fraction, the $S_{\text {number }}$ clearly encompasses the fact that segregation is facilitated when $\Delta \rho$ and $A_{c}$ are high and that segregation is limited for high pressure gradient $P_{d}$ and/or large dyke width $W_{d}$ (Yamato et al., 2012).

The value of $P_{d}$ cannot be directly estimated from field observations and/or petrological studies. However, upper/lower bounds on the ascending magma maximum velocity $\left(U_{a m}\right)$ can sometimes be estimated. Hence, it is convenient to express Eq. 8 in terms of $U_{a m}$ using the pressure gradient formula (see Appendix A in Yamato et al., 2012), which yields:

$$
S_{\text {number }}=\frac{\Delta \rho g A_{c}}{8 \eta_{\text {am }} U_{\text {am }}},
$$

where $\eta_{a m}$ corresponds to the effective viscosity (i.e., the shear viscosity of a representative volume of an aggregate comprising both solid crystals and liquid melt) of the ascending magma. Expressed this way, the $S_{\text {number }}$ corresponds to the inverse of the prediction of Koyaguchi and Blake (1989) for mixing during the rise of a magma batch. As an example, a typical $S_{\text {number }}$ value for an ascending granitic magma considering $A_{c}=0.01 \times 0.01 \mathrm{~m}^{2}, \Delta \rho=250 \mathrm{~kg} \cdot \mathrm{m}^{-3}, U_{a m}=10^{-2} \mathrm{~m} \cdot \mathrm{s}^{-1}$ and $\eta_{a m}=10^{5} \mathrm{~Pa} \cdot \mathrm{s}$ yields $S_{\text {number }} \sim 10^{-5}$. A similar calculation for basaltic material, with $A_{c}=0.01 \times 0.01 \mathrm{~m}^{2}, \Delta \rho=500$ kg.m ${ }^{-3}, U_{a m}=10^{-2} \mathrm{~m} \cdot \mathrm{s}^{-1}$ and $\eta_{a m}=10^{2}$ Pa.s, yields $S_{\text {number }} \sim 10^{-2}$. If ascent rates are 100 times lower (i.e. $U_{a m}=10^{-4} \mathrm{~m} \cdot \mathrm{s}^{-1}$ ), the $S_{\text {number }}$ becomes on the order of $10^{-3}$ and 1 for the granitic and basaltic magmas, respectively. However, while such a formulation (Eq. 9) has the advantage not to explicitly depend on $P_{d}$, it appears not entirely satisfactory because this notation requires the knowledge of the effective viscosity of the ascending magma, which actually corresponds to the 
least constrained parameter. For this reason, and because $P_{d}$ is known in our experiments, we here after compute the $S_{\text {number }}$ according to the Eq. 8.

The $S_{\text {number }}$ defined here corresponds to a non-dimensional number (or ratio) characterising the balance between gravitational and viscosity forces at the scale of the crystal. It does not correspond neither to the Smoluchowski number $\left(S_{m}\right)$ nor to the Stokes number $\left(S_{t}\right)$, and this difference needs to be clarified, especially because the $S_{m}$ number has often been used to distinguish two types of segregation processes (e.g., Bagdassarov et al., 1996a; Bagdassarov and Dorfman, 1998), which could therefore lead to some misunderstanding (see also our discussion in Section 4.2.1.). The Smoluchowski number $\left(S_{m}\right)$ corresponds to the ratio of the gravitational force over the pressure gradient force (e.g., Ramberg 1981, Weijermars and Schmeling, 1986) and is defined as:

$$
S_{m}=\frac{g l_{0}}{p}
$$

where $l, \rho_{0}, \Delta p$ and $g$ are the characteristic length, the density, the pressure difference and the gravitational acceleration, respectively. The Stokes number $\left(S_{t}\right)$ is defined as the ratio between the pressure gradient force and the viscous force (e.g., Ramberg 1981, Weijermars and Schmeling, 1986) such as:

$$
S_{t}=\frac{l \Delta p}{\eta_{c} v}
$$

where $\eta_{c}$ and $v$ correspond to the characteristic viscosity and velocity. $S_{t}$ and $S_{m}$ are useful when studying rocks flowing as a viscous continuum (e.g. Rayleigh-Taylor instabilities; Ramberg, 1981) but they do not correspond to the $S_{\text {number }}$, which is actually equal up to a factor to the Ramberg number $\left(R_{m}\right)$ introduced by Weijermars and Schmeling (1986) such as, for instance, $S_{\text {number }}=\frac{1}{8} R_{m}$ if $\quad={ }_{0}$ (see Eq. 9-11). $R_{m}, S_{t}, S_{m}$ and the $S_{\text {number }}$ are thus related by $R_{m}=S_{t} \times S_{m} \mu S_{\text {number }}$. Since the $S_{\text {number }}$ allows, for a given crystal fraction, to estimate the amount of segregation, we prefer to discuss our results in terms of the " $S_{\text {number }}$ " instead of " $R_{m}$ " as it is explicitly tailored to the context of our study (we note that in Ramberg (1981), the ratio between the gravity force and the viscous 
force was a nameless ratio).

We conducted numerical simulations using different input parameters but with the same $S_{\text {number }}$ (Fig. 8). At a given crystal volume percentage $\varphi$, the results exhibit similar general behaviour. From this we conclude that the parameters related to the ascending flow (i.e. pressure gradient $P_{d}$ and dyke width $W_{d}$ ) and the competing effect induced by the buoyancy of the crystal mass (combination of $\Delta \rho$ and $A_{c}$ ) can be included in such a single expression.

In the case where the ratio of a characteristic crystal length compared to the dyke width is small enough (i.e., $L c<1 / 6 \mathrm{Wd}$ ), the dominant parameters controlling the amount of segregation during magma ascent are the crystal fraction $\varphi$ and the $S_{\text {number }}$. This is clearly illustrated in Fig. $6 \mathrm{~b}$, which shows (i) that the amount of segregation highly depends on $\varphi$ ("S" shape presented in Section 3.3. following a cumulative normal distribution) and (ii) that this dependency varies with different values of $\Delta \rho$ (i.e. different $S_{\text {number }}$ ). Moreover, Fig. $6 \mathrm{~b}$ shows that with increasing $S_{\text {number }}$, the mean value of the cumulative distribution increases and the standard deviation decreases.

The amount of segregation occurring during magma ascent in the dyke ( $\mathrm{Seg} *$ ) can be approximated by a cumulative normal distribution law (Fig. 3c and Fig. 6b), which can be expressed as follow:

$$
\operatorname{Seg} \approx \operatorname{Seg}^{*}=1-\frac{1}{2}\left(1+\operatorname{erf}\left(\frac{\varphi-\mu}{\sqrt{2 \sigma^{2}}}\right)\right),
$$

where $\mu$ and $\sigma$ are the mean and the standard deviation of the cumulative normal distribution, respectively. The amount of segregation $\left(\mathrm{Seg}^{*}\right)$ depends on the $S_{\text {number }}$ and the crystal fraction $(\varphi)$. For a given $S_{\text {number, }}$, it is thus possible to fit the segregation values obtained from our numerical experiments and to obtain the corresponding values of $\mu$ and $\sigma$ (Fig. 9a). A statistical fit was obtained using experiments described by different $S_{\text {number }}$ presented in Fig. $6 \mathrm{~b}$ and additional 
simulations for a $S_{\text {number }}=5\left(\Delta \rho=1600 \mathrm{~kg} \cdot \mathrm{m}^{-3}\right)$. The obtained results are plotted in Fig. $9 \mathrm{~b}$ for $\mu$ and in Fig. 9c for $\sigma$ as a function of the $S_{\text {number }}$. The dependency of $\mu$ to the $S_{\text {number }}$ follows a linear function in the semi-log space and can thus be described by the following equation:

$$
\mu=A_{\mu} \log _{10}\left(S_{\text {number }}\right)+B_{\mu},
$$

which depends on the two constants $A_{\mu}$ and $B_{\mu}$. The best fit of the data provided by our numerical experiments gives $A_{\mu}=22.8$ and $B_{\mu}=21.3(\mathrm{R}$-square $=0.9791)$. The dependency of $\sigma$ to the $S_{\text {number }}$ was obtained using a similar approach (Fig. 9c). The data from our simulations were fitted using an exponential function:

$$
\sigma=A_{\sigma} \exp \left(B_{\sigma} \cdot S_{\text {number }}\right)
$$

which also depends on two constants $A_{\sigma}$ and $B_{\sigma}$. The best fit of our numerical results yields $A_{\sigma}=$ 9.799 and $B_{\sigma}=-0.3339(\mathrm{R}$-square $=0.9723)$.

To summarise, based on our detailed parametric study we propose the following law for predicting the amount of segregation occurring in a magma ascending in a dyke for a given crystal fraction and a given $S_{\text {number }}$ :

$$
\operatorname{Seg}^{*}=1-\frac{1}{2}\left(1+\operatorname{erf}\left(\frac{\varphi-\left(A_{\mu} \log _{10}\left(S_{\text {number }}\right)+B_{\mu}\right)}{\sqrt{2} A_{\sigma} \exp \left(B_{\sigma} S_{\text {number }}\right)}\right)\right),
$$

Fig. 9d displays the segregation as a function of $\varphi$ and $S_{\text {number }}$, with an extended part shown in Fig. 9e focusing on values of $S_{\text {number }}$ between 0 and 3. For $S_{\text {number }}=0$ (e.g. $P_{d} \rightarrow \infty, W_{d} \rightarrow \infty, \Delta \rho=0$, or $\left.A_{c}=0\right)$, no segregation takes place. At a low $S_{\text {number }}(0-5)$, the transition between $100 \%$ and $0 \%$ of 
segregation occurs over a wide range of crystal volume percentage (up to 45\%). The range of crystallinity over which this transition takes place decreases with increasing $S_{\text {number }}$. Finally, for large $S_{\text {number }}$ (e.g. $P_{d} \rightarrow 0$, high $\Delta \rho$ or $A_{c}$ ), segregation occurs mainly by sedimentation (or mush compaction) in the reservoir that could represent a deep-seated magma chamber alimenting a dyke, and may occur at larger crystallinity. This prediction is however derived for low values of $S_{\text {number }}$, which we regard as representative for dykes (see above).

\section{Discussion}

\subsection{Limitations of our model}

Concerning the numerical method we used, we note that the velocity field obtained from solving the Stokes flow problem is continuous and defined over the whole model domain (i.e. inside both the melt and the crystal domains), which consistently couples both the melt and crystal phases. An immediate benefit of such an approach is that it avoids the requirement to impose special rules (i) to describe the updated position and orientation of the crystal at each time step (e.g. by imposing Newton's law of rigid-body motion), and (ii) to avoid crystal interpenetration (e.g. Suckale et al, 2012a). As a result, in our model, all inter-particle interactions (collisions, viscous drag coupling) are intrinsically taken into account. Nevertheless, our numerical methodology suffers from two limitations. Firstly, the pressure field around each crystal is not accurately resolved due to the fact that we do not explicitly mesh material interfaces. Nevertheless, the overall pressure distribution around inclusions is consistent with those obtained using body fitted finite element methods only if a sufficiently high spatial resolution is used (see Yamato et al., 2012 and comparison with Schmid and Podladchikov, 2003). Since our models do not employ pressure dependent rheologies, this attribute will not impact our results, which principally focuses on the amount of segregation. Secondly, the discrete system of equations is solved using sparse direct LU factorisation. Whilst suitable for $2 \mathrm{D}$ simulations, such solvers are not appropriate for $3 \mathrm{D}$ discretisations due to their 
increased algorithmic complexity, which causes a large increase in both the required CPU time and memory. The developments of robust iterative methods to circumvent this limitation are currently underway. Consequently, at the present time, we are unable to perform three-dimensional segregation studies with a numerical resolution equivalent to the 2D models presented in this study.

Concerning the prediction law, it is difficult, at large $S_{\text {number }}(>5)$, to accurately predict the amount of segregation (Fig. 9d). For such parameters (large $\Delta \rho$ or $A_{c}$ ), the transition between 0 and $100 \%$ segregation becomes very sharp and small deviations between the amount of segregation obtained in the numerical models and the scaling prediction are observed. These deviations can reach up to $10 \%$ and may be explained by the "chaotic nature" of our numerical experiments. The amount of segregation in the numerical models is calculated at a quasi-transient stage (Fig. 2d). The aggregation and disaggregation of crystals, however, causes transient fluctuations during the segregation process (e.g. melt pockets formation at high crystal fraction), which probably affects our estimation of the amount of segregation.

Our prediction does not take into account the aspect ratio of the crystals. However, the segregation amount can vary when the long axis of crystals is larger than $\sim 1 / 6$ of the dyke width (Fig. 4). Under this condition, initially randomly oriented crystals may obstruct the conduit, which reduces the final amount of segregation. This could be taken into account in our prediction law by adding the ratio between the characteristic crystal length and the dyke width (additional non-dimensional number). But, as in most natural cases this ratio is small, we considered it as negligible to keep our prediction law in its simplest form. Moreover, crystal sizes and shapes may change (dissolution or crystal growth) during magma ascent (Nicholis and Rutherford, 2004), hence dynamically modifying both the crystal aspect ratios and the effective crystal fraction. Such effects cannot be taken into account in our mechanical models and in the resulting predictions we propose here. Our models also ignore additional parameters such as the possible presence of a gas phase. Although the occurrence of gas bubbles in a flowing magma is critical when studying volcanic processes such as lava magma 
fragmentation and eruption (e.g., Dingwell, 1998; Manga et al., 1998), this parameter is not relevant for our study that focuses on ascent of granitic magmas deeper in the crust, where volatiles are dissolved in the melt phase rather than present as an individual gas phase (e.g., Zhang et al., 2007).

The maximum packing fraction (i.e. the maximum fraction of crystals contained in the magmatic mush) is generally found to be different in 2D and in 3D. For example, in our 2D calculations the segregation mechanism is viable up to crystal volume percentages $\varphi$ of about $40-45 \%$, while the maximum packing fraction is reached for crystal volume percentages $\varphi$ in the range $\sim 50-70 \%$ when considering 3D prismatic crystals (e.g., Marsh, 1981; Vigneresse et al., 1996; Saar et al., 2001). This constitutes another limitation of our study, as it is not straightforward to apply our scaling law to $3 \mathrm{D}$ systems. Indeed, in nature, crystals are not infinite in the third direction and the resulting absolute value of the amount of segregation will be different. However, this study provides constraints on the relative influence of the key physical parameters involved in systems corresponding to ascent of magmas in dykes and paves the way for future models, which will consider the three-dimensionality of this problem.

Finally, although the Reynolds number corresponding to our reference experiment is low $\left(\operatorname{Re}=10^{-6}\right.$ i.e. viscous forces dominate the inertial forces), thereby justifying the use of Stokes equations, we tested the impact of inertial effects on our results in Appendix A1. The results suggest that effects of inertia are negligible with respect to crystal-melt segregation during magma ascent, as recently argued by Glazner (2014).

\subsection{Comparison with previous studies}

\subsubsection{Segregation amount vs. segregation processes}


The prediction law provided here (Eq. 15) allows predicting the amount of segregation for any given dyke, knowing the $S_{\text {number }}$ and the crystal fraction $\varphi$. However as it differs from the Smoluchowski number $S_{m}$ (see Section 3.4.), the $S_{\text {number }}$ cannot be used to characterise the processes by which segregation occurs (controlled by compaction or by differential stress), which requires the knowledge of the shear stress or differential stress (Bagdassarov et al., 1996a; Bagdassarov and Dorfman, 1998). The average of the second invariant of the stress tensor $\left(\sigma_{I I}\right)$ can be, however, computed through time in our numerical experiments, which allows us to compute the $S_{m}$ number, as defined by Bagdassarov et al. (1996a). For the five simulations illustrated in Fig. 5 (segregation as a function of the crystal fraction) for example, the $S_{\text {number }}$ does not change since it is independent of the crystal volume percentage $\varphi$. In contrast, the average of $\sigma_{I I}$ (at $t=40000 \mathrm{~s}$ ) values are drastically different $\left(\sigma_{I I} \sim 7.4,16.7,41.8,699.9\right.$ and $4.7 \mathrm{e} 4 \mathrm{~Pa}$ for $\varphi=5 \%, 15 \%, 25 \%, 35 \%$ and $45 \%$, respectively), which yields very different $S_{m}$ number $\left(S_{m} \sim 407,179,72,4\right.$ and 0.06, respectively). This shows that processes resulting in the limited amounts of crystal-melt segregation observed for high crystal contents are linked to differential stress, while segregation is mainly driven by compaction at low crystal fractions. The $S_{m}$ number provides important insights regarding the process governing crystal-melt segregation but its computation requires the measurement of the shear stress. The advantage of the $S_{\text {number }}$ is that it can be directly computed for any given dyke and it thus allows us to quantify the crystal-melt segregation when combined with estimates of the crystal fraction $\varphi$.

\subsubsection{Segregation prediction}

Our results indicate that when the viscous force is larger than the gravitational force (i.e. $S_{\text {number }}<1$ ), crystal-melt segregation will be limited and will only take place at low crystal content (Fig. 9d). For $S_{\text {number }}$ values higher than 1, however, crystal-melt segregation is likely to occur for crystallinities up to $\varphi$ values of 40 to $45 \%$ during magma ascent in dyke. At low crystal content, the melt phase remains connected and the drag exerted by the crystals on the melt is limited. This condition 
enhances density-driven crystal melt separation. At higher crystal fractions, the close crystal packing leads to crystal aggregation. As a consequence the melt is trapped in pockets located between the crystal aggregates. In this setting, the fluid and solid phases are transported coherently through the conduit. The amount of segregation is hence considerably lowered for high crystal contents. This result contrasts with that of Dufek and Bachman (2010), which predicted an optimal segregation window at high crystal volume percentage (50-70\%). Their results were related to the cooling of a crystallising crystal mush. In a convection setting and at low crystal content, crystals are entrained with the melt flow thus minimising crystal-melt separation and segregation. Crystalmelt separation is facilitated at higher crystal fractions where the spatial crystal distribution may allow the development of melt channels allowing its extraction. In this setting, segregation is enhanced until the crystal fraction reaches an upper bound and the melt phase remains trapped in isolated pockets (crystal lock-up). The experimental conditions for which the results of Dufek and Bachman (2010) were obtained (i.e., crystallising sill) and those of our study (i.e., magma flowing in a vertical conduit) differ significantly and are most probably the cause of this apparent discrepancy.

\subsubsection{Magma rheology}

Understanding the rheology of crystal bearing magmas has first order implication for volcanism and lithosphere dynamics, and it has thus been the topic of numerous studies (e.g. Bottinga and Weill, 1972; Shaw, 1972; Murase and McBirney, 1973; Marsh, 1981; Spera et al., 1988; Bagdassarov et al., 1994; Lejeune and Richet, 1995; Vigneresse et al., 1996; Bagdassarov and Dorfman, 1998; Manga et al., 1998; Petford and Koenders, 1998; Saar et al., 2001; Petford, 2003; Rabinowicz and Vigneresse, 2004; Rosenberg and Handy, 2005; Cordonnier et al., 2012; Pistone et al., 2013). Experimental studies have reported that magmas may deform in a non-linear manner (e.g. Lejeune and Richet, 1995) but the mechanisms that cause this behaviour are still a matter of debate (Deubelbeiss et al., 2011, Cordonnier et al., 2012). In our crystal-bearing magma ascent numerical 
experiments, the flow profiles exhibit Bingham-like shape (see Yamato et al., 2012). The employed fluid and solid phase rheologies are both linear viscous and neither plasticity nor shear heating are considered. This Bingham-like behaviour is hence only related to the internal disposition of the crystals within the magma, which act as rigid obstacles disturbing the flow of the fluid phase. The Bingham-like rheology is thus only apparent and is strongly time-dependent as the spatial crystal distribution is constantly rearranging during the ascent of the magma in the dyke.

\subsection{Geological implications}

Our study allows to test whether crystals would tend to remain in a magma ascending in the crust via dyking or whether they would be more likely to segregate and remain trapped at depth. We provide here three scenarios illustrating how these results could be used for given magmatic systems. The parameters that need to be known to estimate the $S_{\text {number }}$ are the density contrast $\Delta \rho$ between crystals and the melt phase, the crystal size $A_{c}$, the magma ascent velocity $U_{a m}$ and its effective viscosity $\eta_{m}$ (see Eq. 9). To a first order, the effective viscosity of a magma $\eta_{a m}$ depends on the viscosity of the melt phase and on the volume percentage $\varphi$ of crystals. In the following examples we consider $\varphi$ values in the range $25-30 \%$, which results in an increase of $\eta_{a m}$ by $\sim 0.5 \log$ units compared to the viscosity of the melt phase (e.g., Caricchi et al., 2007). A summary of the parameters used for the different examples and the corresponding $S_{\text {number }}$ estimates is reported in Table 1.

The first example investigates the feasibility for olivine phenocrysts to segregate from an ascending kimberlitic magma. We selected a typical viscosity of $\sim 10$ Pa.s for the kimberlitic magma, densities of $2900 \mathrm{~kg} \cdot \mathrm{m}^{-3}$ for the melt phase and $3300 \mathrm{~kg} \cdot \mathrm{m}^{-3}$ for the $0.005 \mathrm{~m} \times 0.005 \mathrm{~m}$ olivine (Fo90) crystals, and an ascending velocity of 5 m.s ${ }^{-1}$ (e.g. Sparks et al., 2006; Kopylova et al., 2007; Russell et al., 2012), resulting in a $S_{\text {number }}$ around $10^{-4}$. Using Eq. 15 yields $S e{ }^{*} \sim 0$ for any value of $\varphi$, indicating that segregation of small olivine phenocrysts during ascent of a typical kimberlitic 
magma will be negligible whatever the magma crystallinity is, since the very fast ascending velocities of kimberlitic magmas likely hampers effective crystal-melt segregation.

The second example investigates the feasibility of crystal-melt segregation for basaltic systems, such as the Henties Bay-Outjo dyke swarm that fed the Etendeka large igneous province in Namibia (Keiding et al., 2013). Considering a density of $2700 \mathrm{~kg} \cdot \mathrm{m}^{-3}$ (Keiding et al., 2013) and a viscosity of $\sim 10^{2}$ Pa.s for high temperature basaltic magmas (e.g. Giordano et al., 2008; Laumonier et al., 2014) ascending at $\sim 1.5 \times 10^{-3} \mathrm{~m} . \mathrm{s}^{-1}$, which is lower than typical ascent rates determined for ascent at shallow depth but more consistent with ascent rates at depth (Armienti et al., 2013), this gives a $S_{\text {number }}$ of $\sim 10^{-3}$ for $\sim 0.0005 \mathrm{~m} \times 0.0005 \mathrm{~m}$ augitic clinopyroxene crystals (density of $\sim 3400 \mathrm{~kg} \mathrm{~m}^{-3}$; Keiding et al., 2013), and a $S_{\text {number }}$ of $\sim 5 \times 10^{-2}$ for $\sim 0.003 \mathrm{~m} \times 0.003 \mathrm{~m}$ forsteritic olivine crystals (density of $\sim 3300 \mathrm{~kg} \mathrm{~m}^{-3}$; Keiding et al., 2013). The low $S_{\text {number }}$ calculated for the small clinopyroxene crystals suggests that they were unlikely to be segregated from the ascending magma; on the other hand, segregation of small amounts of the larger olivine phenocrysts could have occurred $\left(\mathrm{Seg}^{*} \sim 3 \%\right.$ for $\left.\varphi=10 \%\right)$ during magma ascent in dykes, providing that $\varphi$ values remained lower than $\sim 10-15 \%$ (Fig. 9d).

Finally, we can investigate crystal segregation from highly viscous leucogranitic magmas during their ascent in dykes. Taking a density of $2400 \mathrm{~kg} \cdot \mathrm{m}^{-3}$ (Knoche et al., 1995) and a viscosity of $\sim 10^{5}$ Pa.s for a leucogranite magma with a $\varphi$ value of 25-30\% (Scaillet et al., 1996; Petford, 2003), and an ascent velocity of $\sim 1.0 \times 10^{-6} \mathrm{~m} . \mathrm{s}^{-1}$, much slower than for basaltic magma ascent rates at depth (since leucogranite magmas are $\sim 1000$ times more viscous), yields $S_{\text {number }}$ of $\sim 10^{-1}$ for $\sim 0.01 \mathrm{~m} \times$ $0.01 \mathrm{~m}$ crystals of albitic plagioclase and K-feldspars (density of $\sim 2600 \mathrm{~kg} . \mathrm{m}^{-3}$ ), which is a typical size observed in granitic dykes in deep melt transfer zones (e.g., Morfin et al., 2014). This suggests that feldspar crystals of moderate size can effectively be segregated from ascending viscous leucogranite magmas for moderate $\varphi$ values below $15-20 \%$ (Fig. 9d). For example, Seg ${ }^{*} \sim 11 \%$ for $\varphi=10 \%$. Also, a small increase of the size of the feldspar phenocrysts would tend toward $S_{\text {number }}$ 
values around 1, which would allow very efficient crystal-melt segregation for a large range of $\varphi$ values (Fig. 9d).

Uncertainties in such calculations are large and relate to the range of possible input values, especially for the magma ascent velocity, which is the least constrained parameter. However these first order calculations immediately illustrate why, for similar crystal contents, segregation of feldspars during ascent of granitic magmas through the crust could be a common phenomenon (e.g., Tartèse and Boulvais, 2015; Morfin et al., 2014; Ballouard et al., 2015), while large amounts of olivine phenocrysts and of clastic xenoltihs are commonly observed in kimberlitic magmas (e.g., Mitchell, 1995; Kopylova et al., 2007) due to a very limited amount of segregation.

\section{5 - Conclusions}

This study presents a wealth of 2D numerical models simulating crystal-melt segregation during ascent of magma in a vertical dyke. The extensive parametric study we have carried out shows that only a limited number of parameters control the amount of segregation:

(1) Numerical experiments showed that the initial crystal distribution in the reservoir, as well as the crystal aspect ratio, does not noticeably affect the behaviour of magma flow, and thus does not influence the amount of segregation. The aspect ratio might become important if the long axis is larger than $1 / 6$ of the dyke width. We conclude that this parameter only weakly influences the amount of segregation.

(2) The amount of segregation is dominated by the crystal fraction $(\varphi)$ and the segregation number $\left(S_{\text {number }}\right)$. The amount of segregation decreases when the crystal fraction increases following a cumulative normal distribution law. The segregation number $S_{\text {number }}$ depends on the density contrast between the crystals and the carrying melt, the crystal size, the dyke width and the applied pressure gradient. 
(3) Inertial forces (up to $R e \sim 10$ ) do not significantly influence the segregation process. Only small deviations due to inertia can occur at low melt viscosity ( 10 Pa.s).

The first order scaling law derived from our parametric study allows to directly predict the extent of crystal-melt segregation occurring during upward transport of a magmatic mush in a vertical dyke, and is accurate $( \pm 10 \%)$ for $S_{\text {number }}<10$, which encompasses the common physical parameters related to ascent of basaltic to granitic magmas in dykes through the Earth's continental crust. This work, allowing prediction of the amount of segregation, is complementary to studies that have focused on the processes active during crystal-melt segregation or on effective viscosity of magmatic mushes. Future models in $3 \mathrm{D}$ and integrating the interplay between temperature and chemical processes are necessary to further our understanding of crystal-melt segregation processes, and especially to quantify its relationship with the magma viscosity, which impacts upon the dynamics of all magma types.

\section{Acknowledgments}

The authors wish to thank C. Luisier, E. Tornare, O. Reubi, S. Pilet, T. Keller and B. Kaus for stimulating discussions. P.Y. also thanks K. Gallagher for discussions on fitting methods. Simulations were run on the ETH Brutus computational resource. We also thank J. Suckale and M. Pistone for their constructive reviews, which helped us to improve the manuscript, and K. Wang for the editorial handling.

\section{References}

Armienti, P., Perinelli, C., Dutirka, K.D., 2013. A New Model to Estimate Deep-level Magma Ascent Rates, with Applications to Mt. Etna (Sicily, Italy). Journal of Petrology 54, 795813.

Bagdassarov, N.S., Dingwell, D.B., Webb, S.L., 1994. Viscoelasticity of crystal- and bubble- 
bearing melts. Physics of the Earth and Planetary Interiors 83, 83-99.

Bagdassarov, N.S., Dorfman A.M., Dingwell D.B., 1996a. Modelling of melt segregation processes by high-temperature centrifuging of partially molten granites - I. Melt extraction by compaction and deformation. Geophysical Journal International 127, 616-626.

Bagdassarov, N.S., Dorfman, A.M., Dingwell, D.B., 1996b. Modelling of melt segregation processes by high-temperature centrifuging of partially molten granites - II. RayleighTaylor instability and sedimentation. Geophysical Journal International 127, 627-634.

Bagdassarov, N.S., Dorfman A.M., 1998. Granite rheology: magma flow and melt migration. Journal of the Geological Society, London, 155, 863-872.

Bagnold, R.A., 1954. Experiments on a gravity-free dispersion of large solid spheres in a Newtonian fluid under shear. Proceedings of the Royal Society of London, Series A, Mathematical and Physical Sciences 225, 49-63. doi: 10.1098/rspa.1954.0186

Ballouard, C., Boulvais, P., Poujol, M., Gapais, D., Yamato, P., Tartèse, R., Cuney, M. 2015. Tectonic record, magmatic history and hydrothermal alteration in the Hercynian Guérande leucogranite, Armorican Massif, France. Lithos, in press, doi: 10.1016/j.lithos.2015.01.027.

Barboni, M., Schoene, B., 2014. Short eruption window revealed by absolute crystal growth rates in a granitic magma. Nature Geoscience 7, 524-528. doi:10.1038/ngeo2185.

Barrière, M., 1976. Flowage differentiation: limitation of the "Bagnold effect" to the narrow intrusions. Contributions to Mineralogy and Petrology 55, 139-145.

Bottinga, Y., Weill, D.F., 1972. The viscosity of magmatic silicate liquids. American Journal of Science 272, 438-475.

Bowen, N. L., 1928. The evolution of the igneous rocks: Princeton, New Jersey, Princeton University Press, 334 p.; second edition, 1956, New York, Dover.

Brown, M., Averkin, Y.A., McLellan, E.L., Sawyer, E.W., 1995. Melt segregation in migmatites. Journal of Geophysical Research: Solid Earth 100, 15655-15679. doi:10.1029/95JB00517

Caricchi, L., Burlini, L., Ulmer, P., Gerya, T., Vassalli, M., Papale, P., 2007. Non-Newtonian rheology of crystal-bearing magmas and implications for magma ascent dynamics. Earth 
and Planetary Science Letters 264, 402-419. doi:10.1016/j.eps1.2007.09.032

Caricchi, L., Giordano, D., Burlini, L., Ulmer, P., 2008. Rheological properties of magma from the 1538 eruption of Monte Nuovo (Phlegrean Fields, Italy): an experimental study. Chemical Geology 256, 158-171.

Cimarelli, C., Costa, A., Mueller, S., Mader, H.M., 2011. Rheology of magmas with bimodal crystal size and shape distributions: Insights from analog experiments. Geochemistry, Geophysics, Geosystems 12, Q07024, doi:10.1029/2011GC003606

Clemens, J.D., Mawer, C.K., 1992. Granitic magma transport by fracture propagation. Tectonophysics 204, 339 - 360. doi:http://dx.doi.org/10.1016/0040-1951(92)90316-X

Clemens, J.D., 1998. Observations on the origins and ascent mechanisms of granitic magmas. Journal of the Geological Society 155, 843-851. doi: 10.1144/gsjgs.155.5.0843

Clemens, J.D., Petford, N., 1999. Granitic melt viscosity and silicic magma dynamics in contrasting tectonic settings. Journal of the Geological Society 156, 1057-1060. doi: 10.1144/gsjgs.156.6.1057

Cordonnier, B., Schmalholz, S. M., Hess, K.-U., Dingwell, D. B., 2012. Viscous heating in silicate melts: An experimental and numerical comparison. J. Geophys. Res. 117, B02203, doi:10.1029/2010JB007982.

Costa, A., Caricchi, L., Bagdassarov, N., 2009. A model for the rheology of particle-bearing suspensions and partially molten rocks. Geochemistry, Geophysics, Geosystems 10, Q03010, doi:10.1029/2008GC002138

Deubelbeiss, Y., Kaus, B.J.P., Connolly, J.A.D., Caricchi, L., 2011. Potential causes for the nonNewtonian rheology of crystal-bearing magmas, Geochem. Geophys. Geosyst. 12, Q05007, doi:10.1029/2010GC003485.

Dingwell, D.B., 1998. Magma degassing and fragmentation: recent experimental advances. A. Freundt, M. Rosi (Eds.), From Magma to Tephra. Modelling Physical Processes of Explosive Volcanic Eruptions, Elsevier, Amsterdam, pp. 1-23

Dufek, J., Bachmann, O., 2010. Quantum magmatism: Magmatic compositional gaps generated by 
melt-crystal dynamics. Geology 38, 687-690. doi:10.1130/G30831.1

Dufek, J., Bergantz, G.W., 2005. Transient two-dimensional dynamics in the upper conduit of a rhyolitic eruption: A comparison of closure models for the granular stress. Journal of Volcanology and Geothermal Research 143, 113-132. doi:10.1016/j.jvolgeores.2004.09.013

Duretz, T., May, D.A., Gerya, T.V., Tackley, P.J., 2011. Discretization errors and free surface stabilization in the finite difference and marker-in-cell method for applied geodynamics: A numerical study. Geochemistry, Geophysics, Geosystems 12, Q07004, doi:10.1029/2011GC003567

Fountain, J.C., Hodge, D.S., Shaw, R.P., 1989. Melt segregation in anatectic granites: A thermomechanical model. Journal of volcanology and geothermal research 39, 279-296.

Fourmentraux, C., Métrich, N., Bertagnini, A., Rosi, M., 2012. Crystal fractionation, magma step ascent, and syn-eruptive mingling: the Averno 2 eruption (Phlegraean Fields, Italy). Contributions to Mineralogy and Petrology 163, 1121-1137.

Frehner, M., Schmalholz, S.M., 2006. Numerical simulations of parasitic folding in multilayers. Journal of Structural Geology 28, 1647-1657.

Gerya, T.V., Yuen, D.A., 2003. Characteristics-based marker-in-cell method with conservative finite-differences schemes for modeling geological flows with strongly variable transport properties. Physics of the Earth and Planetary Interiors 140, 293-318. doi:10.1016/j.pepi.2003.09.006

Giordano, D., Russell, J.K., Dingwell, D.B., 2008. Viscosity of magmatic liquids: A model. Earth and Planetary Science Letters 271, 123-134.

Glazner, A.F., 2014. Magmatic life at low Reynolds number. Geology 42, 935-938. doi: 10.1130/G36078.1

Hawkesworth, C.J., Kemp, A.I.S., 2006. The differentiation and rates of generation of the continental crust. Chemical Geology 226, 134-143. doi: 10.1016/j.chemgeo.2005.09.017

Huppert, H.E., Sparks, R.S.J., 1989. Chilled margins in igneous rocks. Earth and Planetary Science Letters 92, 397-405. doi:10.1016/0012-821X(89)90063-0 
Katz, R.F., Spiegelman, M., Holtzman, B., 2006. The dynamics of melt and shear localization in partially molten aggregates. Nature 442, 676-679. doi:10.1038/nature05039

Keiding, J.,K., Frei, O., Renno, A.D., Veksler, I.V., Trumbull, R.B., 2013. Conditions of magma crystallization in the Henties Bay-Outjo dyke swarm, Namibia: Implications for the feeder system of continental flood basalts. Lithos 179, 16-27.

Keller, T., May, D.A., Kaus, B.J.P., 2013. Numerical modelling of magma dynamics coupled to tectonic deformation of lithosphere and crust. Geophysical Journal International 195, 14061442. doi:10.1093/gji/ggt306

Knoche, R., Dingwell, D.B., Webb, S.L., 1995. Melt densities for leucogranites and granitic pegmatites: Partial molar volumes for $\mathrm{SiO}_{2}, \mathrm{Al}_{2} \mathrm{O}_{3}, \mathrm{Na}_{2} \mathrm{O}, \mathrm{K}_{2} \mathrm{O}, \mathrm{Li}_{2} \mathrm{O}, \mathrm{Rb}_{2} \mathrm{O}, \mathrm{Cs}_{2} \mathrm{O}, \mathrm{MgO}$, $\mathrm{CaO}, \mathrm{SrO}, \mathrm{BaO}, \mathrm{B}_{2} \mathrm{O}_{3}, \mathrm{P}_{2} \mathrm{O}_{5}, \mathrm{~F}_{2} \mathrm{O}_{-1}, \mathrm{TiO}_{2}, \mathrm{Nb}_{2} \mathrm{O}_{5}, \mathrm{Ta}_{2} \mathrm{O}_{5}$, and $\mathrm{WO}_{3}$. Geochimica et Cosmochimica Acta 59, 4645-4652. doi: 10.1016/0016-7037(95)00328-2

Kopylova, M.G., Matveev, S., Raudsepp, M., 2007. Searching for parental kimberlite melt. Geochimica et Cosmochimica Acta 71, 3616-3629.

Koyaguchi, T., Blake, S., 1989. The dynamics of magma mixing in a rising magma batch. Bulletin of volcanology 52, 127-137.

Laumonier, M., Scaillet, B., Pichavant, M., Champallier, R., Andujar, J., Arbaret, L., 2014. On the conditions of magma mixing and its bearing on andesite production in the crust. Nature communications 5, 5607, doi: 10.1038/ncomms6607

Lejeune A.-M., Richet, P., 1995. Rheology of crystal-bearing silicate melts: An experimental study at high viscosities. Journal of Geophysical Research 100, 4215-4229.

Manga, M., J. Castro, K.V. Cashman, and M. Loewenberg, 1998. Rheology of bubble-bearing magmas: Theoretical results. Journal of Volcanology and Geothermal Research 87, 15-28.

Marsh, B.D., 1981. On the crystallinity, probability of occurence, and rheology of lava and magma. Contributions to Mineralogy and Petrology 78, 85-98.

Marsh, B.D., 2013. On some fundamentals of igneous petrology. Contributions to Mineralogy and Petrology 166, 665-690. doi:10.1007/s00410-013-0892-3 
McKenzie, D., 1984. The generation and compaction of partially molten rock. Journal of Petrology $25,713-765$.

McKenzie, D., 1985. The extraction of magma from the crust and mantle. Earth and Planetary Science Letters 74, 81 - 91. doi:http://dx.doi.org/10.1016/0012-821X(85)90168-2

Mitchell, R.H., 1995. Kimberlites, orangeites, and related rocks. Plenum Press, New York and London. 410 p.

Morfin, S., Sawyer, E.W., Bandyayer, D., 2014. The geochemical signature of a felsic injection complex in the continental crust: Opinaca Subprovince, Quebec. Lithos 196-197, 339-355.

Mueller, S., Llewellin, E.W., Mader, H.M., 2010. The rheology of suspensions of solid particles. Proceedings of the Royal Society A: Mathematical, Physical and Engineering Sciences 466, 1201-1228. doi:10.1098/rspa.2009.0445

Mueller, S., Llewellin, E.W., Mader, H.M., 2011. The effect of particle shape on suspension viscosity and implications for magmatic flows, Geophysical Research Letters 38, L13316. doi:10.1029/2011GL047167

Murase, T., McBirney, A.R., 1973. Properties of some common igneous rocks and their melts at high temperatures. Geological Society of America Bulletin 84, 3563-3592.

Nicholis, M.G., Rutherford, M.J., 2004. Experimental constraints on magma ascent rate for the Crater Flat volcanic zone hawaiite. Geology 32, 489-492.

Nicolas, A., 1986. A melt extraction model based on structural studies in mantle peridotites. Journal of Petrology 27, 999-1022.

Petford, N., 2003. Rheology of granitic magma during ascent and emplacement. Annual Review of Earth and Planetary Sciences 31, 399-427, doi: 10.1146/annurev.earth.31.100901.141352.

Petford, N., Koenders, M.A., 1998. Granular flow and viscous fluctuations in low Bagnold number granitic magmas. Journal of the Geological Society 155, 873-881.

Petford, N., Cruden, A.R., McCaffrey, K.J.W., Vigneresse, J.L., 2000. Granite magma formation, transport and emplacement in the Earth's crust. Nature, 408, 669-673.

Philpotts, A.R., Shi, J., Brustman, C., 1998. Role of plagioclase crystal chains in the differentiation 
of partly crystallized basaltic magma. Nature, 395, 343-346.

Picard, D., Arbaret, L., Pichavant, M., Champallier, R., Launeau, P., 2013. The rheological transition in plagioclase-bearing magmas, J. Geophys. Res. Solid Earth, 118, 1-15, doi:10.1002/jgrb.50091

Pistone, M., Caricchi, L., Ulmer P., Reusser E., Ardia, P., 2013. Rheology of volatile-bearing crystal mushes: Mobilization vs. viscous death. Chemical Geology 345, 16-39.

Prosperetti, A., Tryggvason, G., 2007. Computational methods for multiphase flow. Cambridge University Press.

Rabinowicz, M., Vigneresse, J.L., 2004. Melt segregation under compaction and shear channeling: Application to granitic magma segregation in a continental crust. Journal of Geophysical Research 109. B04407, doi:10.1029/2002JB002372

Ramberg, H., 1981. Gravity, Deformation and the Earth's crust. Academic Press, London, $2^{\text {nd }}$ ed., 452 pp.

Rosenberg, C.L., Handy, M.R., 2005. Experimental deformation of partially melted granite revisited: implications for the continental crust. Journal of Metamorphic Geology 23, 19-28.

Russell, J.K., Porritt, L.A., Lavallée, Y., Dingwell, D.B., 2012. Kimberlite ascent by assimilationfuelled buoyancy. Nature 481, 352-356. doi:10.1038/nature10740.

Saar, M.O., Manga, M., Cashman, K.V., Fremouw, S. 2001. Numerical models of the onset of yield strength in crystal-melt suspensions. Earth and Planetary Science Letters 187, 367-379.

Saar, M.O., Manga, M., 2002. Continuum percolation for randomly oriented soft-core prisms. Phys. Rev., E 65, 056131.

Scaillet, B., Holtz, F., Pichavant, M., Schmidt, M., 1996. Viscosity of Himalayan leucogranites: Implications for mechanisms of granitic magma ascent. Journal of Geophysical Research $101,27691-27699$.

Schenk, O., Gärtner, K., 2004. Solving unsymmetric sparse systems of linear equations with PARDISO. Future Generation Computer Systems 20, 475-487.

Schmid, D.W., Podladchikov, Y.Y., 2003. Analytical solutions for deformable elliptical inclusions 
in general shear. Geophys. J. Int. 155, 269-288.

Scott, D.R., Stevenson, D.J., 1986. Magma ascent by porous flow. Journal of Geophysical Research: Solid Earth 91, 9283-9296. doi:10.1029/JB091iB09p09283

Shaw, H.R., 1972. Viscosities of magmatic silicate liquids: an empirical method of prediction. American Journal of Science 272, 870-893.

Sisson, T.W., Bacon, C.R., 1999. Gas-driven filter pressing in magmas. Geology 27, 613-616.

Solgadi, F., Sawyer, E.W., 2008. Formation of igneous layering in granodiorite by gravity flow: a field, microstructure and geochemical study of theTuolumne intrusive suite at Sawmill Canyon, California. Journal of Petrology 49, 2009-2042. doi:10.1093/petrology/egn056

Sparks, R.S.J., Baker, L., Brown, R.J., Field, M., Schumacher, J., Stripp, G., Walters, A., 2006. Dynamical constraints on kimberlite volcanism. Journal of Volcanology and Geothermal Research 155, 18-48.

Spera, F.J., Borgia, A., Strimple, J., Feigenson, M.D., 1988. Rheology of melts and magmatic suspensions: design and calibration of concentric cylinder viscometer with application to rhyolitic magma. Journal of Geophysical Research 93, 10273-10294.

Suckale, J., Sethian, J.A., Yu, J., Elkins-Tanton, L.T., 2012a. Crystals stirred up: 1. Direct numerical simulations of crystal settling in nondilute magmatic suspensions. Journal of Geophysical Research 117. doi:10.1029/2012JE004066

Suckale, J., Elkins-Tanton, L.T., Sethian, J.A., 2012b. Crystals stirred up: 2. Numerical insights into the formation of the earliest crust on the Moon. Journal of Geophysical Research 117. doi:10.1029/2012JE004067

Tartèse, R., Boulvais, P., 2010. Differentiation of peraluminous leucogranites "en route" to the surface. Lithos 114, 353-368. doi:10.1016/j.lithos.2009.09.011

Taylor, S.R., McLennan, S.M., 1995. The geochemical evolution of the continental crust. Reviews of Geophysics 33, 241-265. doi: 10.1029/95RG00262

Turcotte, D.L., Schubert, G., 2002. Geodynamics. Cambridge University Press. 456 pp.

Vernon, R.H., 1986. K-feldspar megacrysts in granites - Phenocrysts, not porphyroblasts. Earth 
Vernon, R.H., Paterson, S.R., 2008. How late are K-felspar megacrysts in granites ? Lithos 104, 327-336. doi:10.1016/j.lithos.2008.01.001

Vigneresse, J.L., Barbey, P., Cuney, M., 1996. Rheological transitions during partial melting and crystallization with application to felsic magma ségrégation and transfert. Journal of Petrology, 37, 6, 1579-1600.

Vigneresse, J.L., Clemens, J.D., 2000. Granitic magma ascent and emplacement: neither diapirism nor neutral buoyancy. Geological Society, London, Special Publications 174, 1-19. doi:10.1144/GSL.SP.1999.174.01.01

Weijermars, R., Schmeling, H., 1986. Scaling of Newtonian and non-Newtonian fluid dynamics without inertia for quantitative modelling of rock flow due to gravity (including the concept of rheological similarity). Physics of the Earth and Planetary Interiors 43, 316-330.

Yamato, P., Tartèse, R., Duretz, T., May, D.A., 2012. Numerical modelling of magma transport in dykes. Tectonophysics 526-529, 97-109. doi:10.1016/j.tecto.2011.05.015

Zhang, Y., Xu, Z., Zhu, M., Wang, H., 2007. Silicate melt properties and volcanic eruptions. Reviews of Geophysics 45, RG4004. doi:10.1029/2006RG000216.

Zhang, Y., Ni, H., Cheng, Y., 2010. Diffusion data in silicate melts. Reviews in Mineralogy \& Geochemistry 72, 311-408. 
Figure 1

a

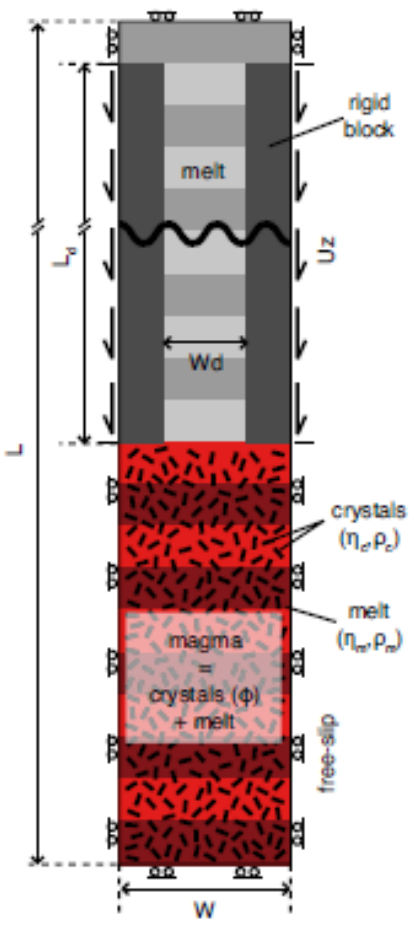

b

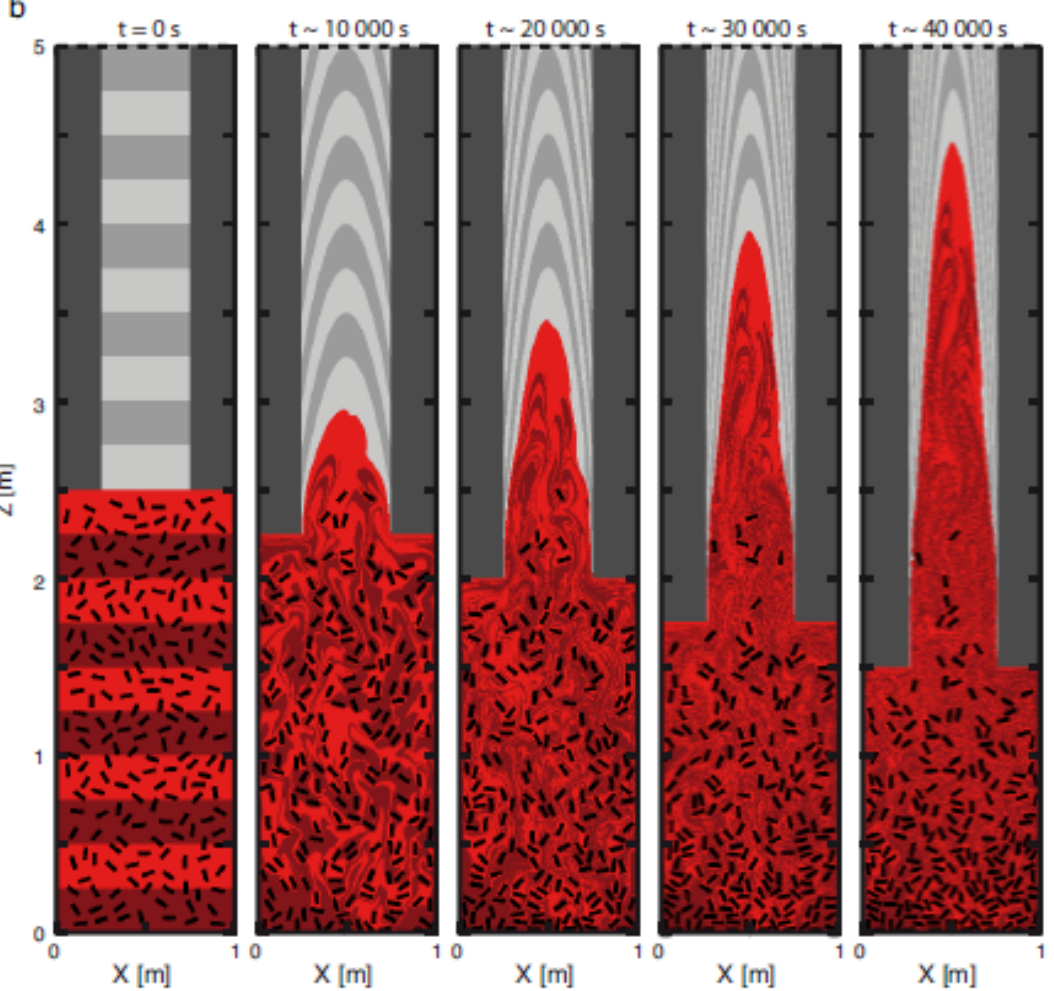

Figure 1. Model setup and reference experiment. Magmatic melt is represented by both the red and light grey regions (the difference in colour enables visualization of the deformation, physical properties are identical), the rigid blocks are indicated by the dark grey regions and crystals are denoted by the black regions. (a) Rigid piston setup simulating an effective pressure gradient between the base and the top of a channel (representing a vertical dyke). The lateral rigid blocks compress the magmatic reservoir with a constant velocity $U_{z}$ inducing a pressure gradient $P_{d}$ along the conduit. The lengths $L, L_{d}, W$ and $W_{d}$ correspond to the length of the model, the length of the dyke, the width of the model and the width of the dyke, respectively. $\eta_{c}, \rho_{c}, \eta_{m}$, and $\rho_{m}$ correspond to the viscosity and the density of the crystals and of the melt, respectively. (b) Evolution of the reference experiment through time exhibiting crystal-melt segregation during magma ascent (Parameters used are: $P_{d}=24 \mathrm{~Pa} \cdot \mathrm{m}^{-1}, \Delta \rho=300 \mathrm{~kg} \cdot \mathrm{m}^{-3}, \varphi=15 \%, A_{c}=$ $\left.0.025 \times 0.075 \mathrm{~m}^{2}\right)$. 
Figure 2

a

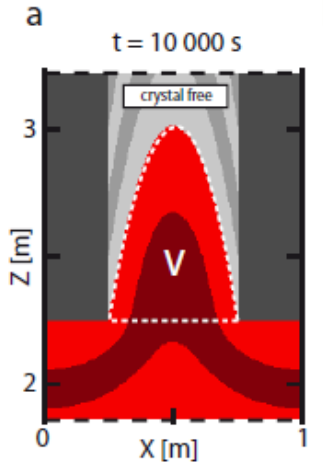

b

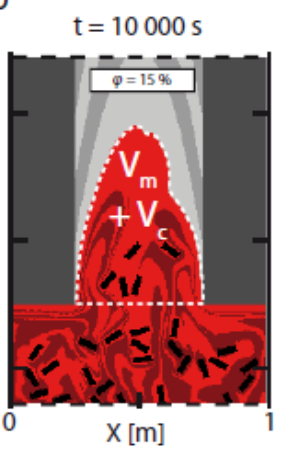

C

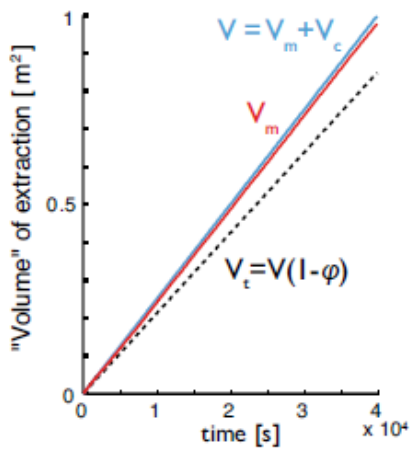

d

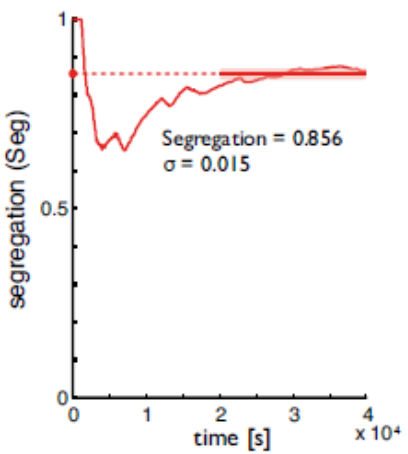

Figure 2. Segregation computation. (a) Model without any crystals. $V$ is the volume of material (only melt here) extracted within the dyke (denoted via dotted white boundary) after $10000 \mathrm{~s}$ of experiment, which fits the analytical solution for a Newtonian fluid in a Poiseuille flow (see Appendix A in Yamato et al., 2012,). (b) Same experiment with $\varphi=15 \% . V_{m}$ and $V_{c}$ correspond to the volume of melt and of crystals extracted from the magmatic reservoir to the dyke, respectively $\left(V=V_{m}+V_{c}\right)$. (c) Evolution of $V, V_{m}$ and $V_{t}$ through time for the reference experiment showed in Fig. 1b. $V_{t}$ corresponds to the theoretical value of melt that would be extracted if the magma would not segregate. (d) Evolution of the amount of segregation (Seg) through time for the reference experiment (see text for details). $\sigma$ stands for standard deviation. 
Figure 3
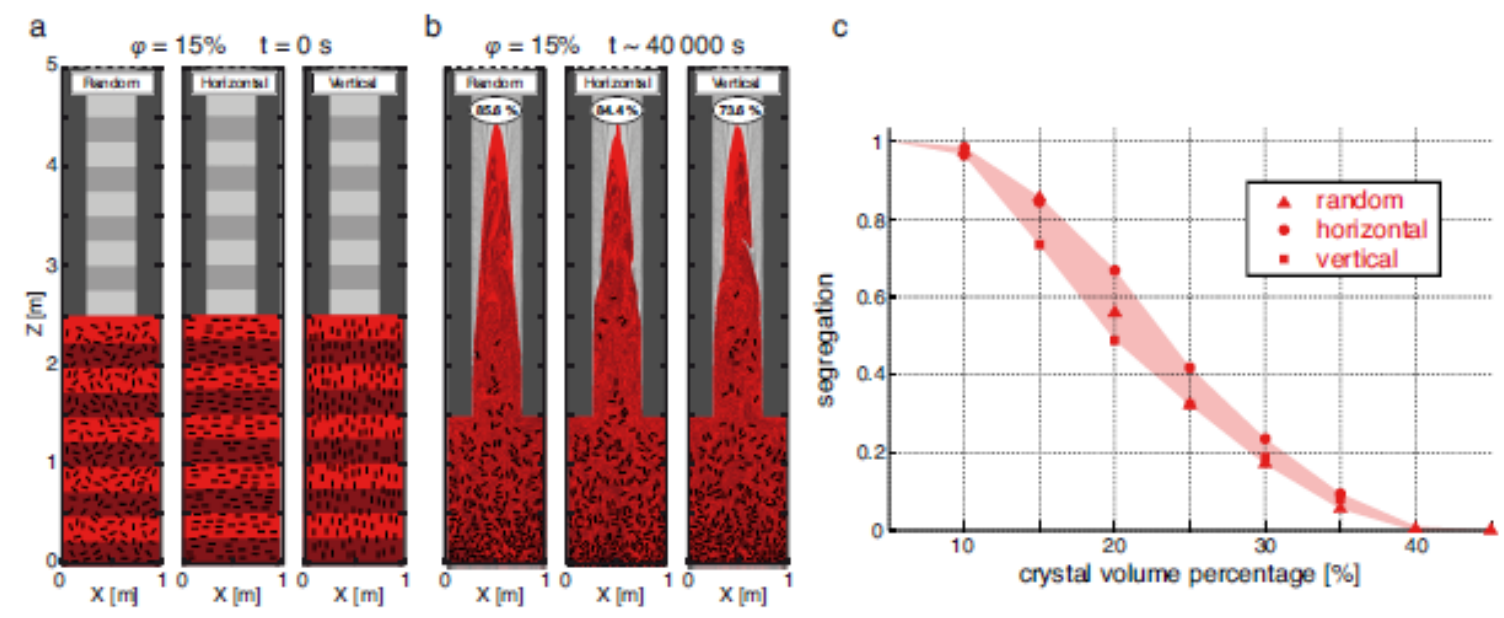

Figure 3. Influence of the initial crystal arrangement. (a) Left: random arrangement (reference experiment), middle: horizontal arrangement, right: vertical arrangement. All other parameters are similar to those used in the reference simulation. (b) Results obtained after $40000 \mathrm{~s}$ for these three numerical experiments. The amount of segregation is indicated in the white ellipse. (c) Values of segregation obtained in these three configurations for different initial crystal volume percentage. Red triangles, squares and dots correspond to the initial random arrangement experiments, the initial horizontal arrangement and the initial vertical arrangement, respectively. Red shaded area corresponds to the variability of the segregation that could be obtained by changing the initial arrangement of the crystals. 
Figure 4

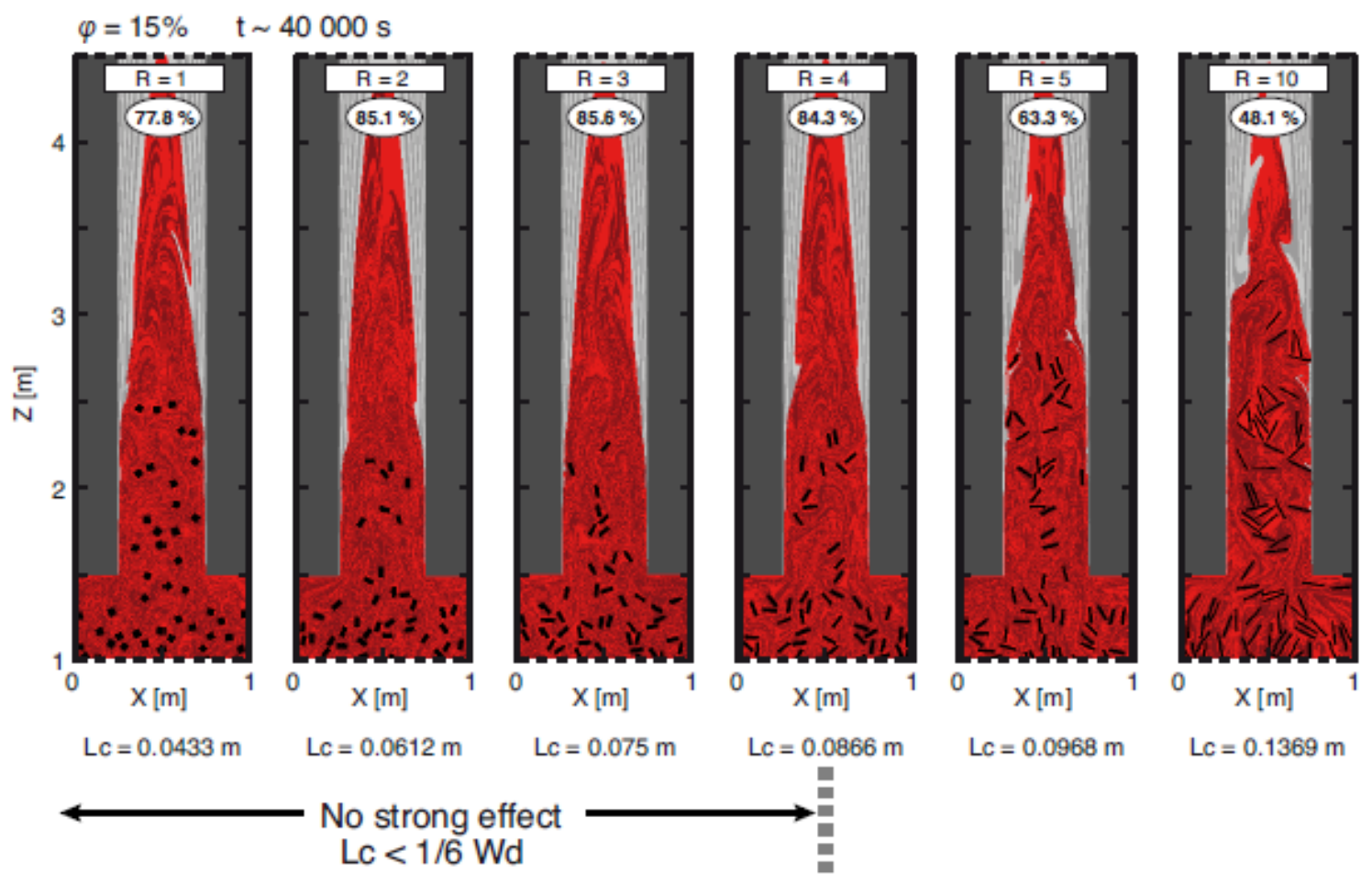

Figure 4. Influence of the crystals aspect ratio $R$. All parameters are identical to those used for the reference experiment except for the aspect ratio of each crystal. Volume of each crystal is also similar (i.e., the area $A_{c}$, and therefore the number of crystals, is the same in each experiment). We vary the ratio $R$ that controls the ratio between the long $\left(L_{c}\right)$ and short axis of the crystals. Computed segregation values are indicated in the white ellipses for each numerical simulation. Results show that $R$ does not significantly influence the amount of segregation value as long as $L_{c}$ is small enough with respect to the width of the dyke $W_{d}$. 
Figure 5
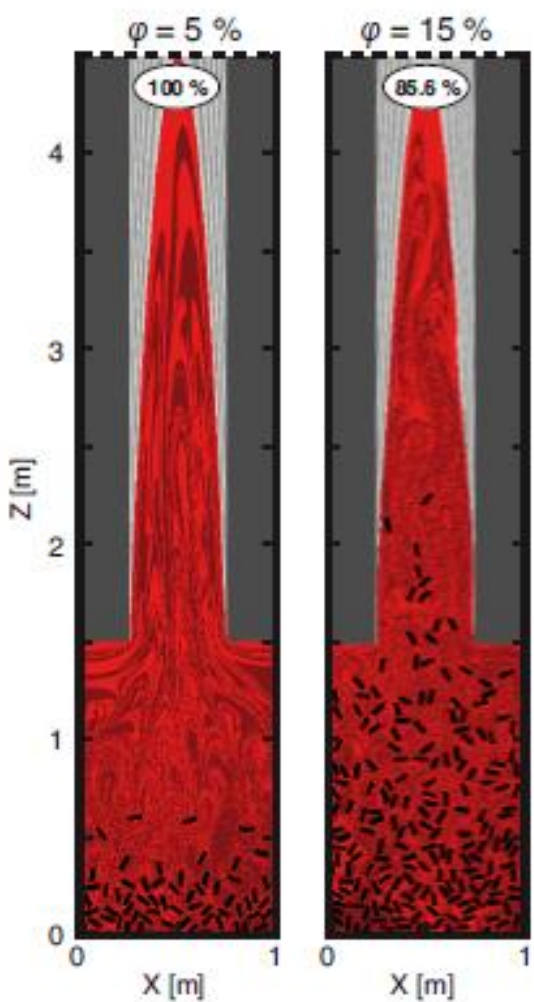

$\mathrm{t} \sim 40000 \mathrm{~s}$
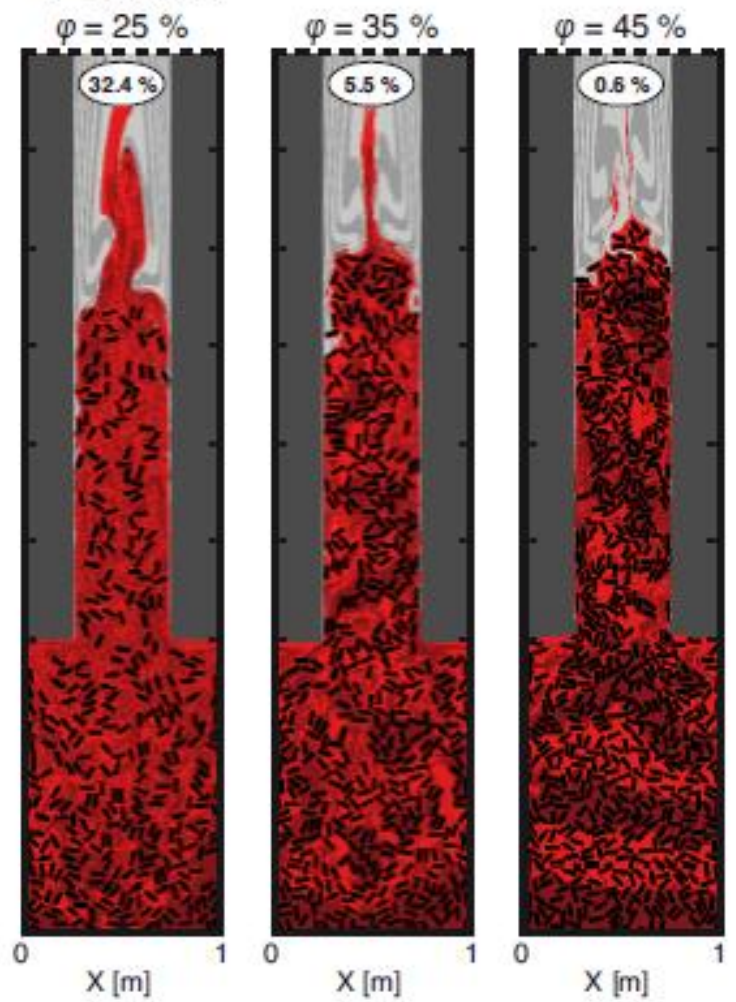

Figure 5. Influence of the crystal volume percentage $\varphi$. Other parameters are the same as those used for the reference experiment. This figure shows the results obtained after $40000 \mathrm{~s}$ of the numerical experiment for $\varphi$ $=5 \%, 15 \%, 25 \%, 35 \%$ and $45 \%$, respectively. Computed segregation values are indicated in the white ellipses for each experiment. 
Figure 6
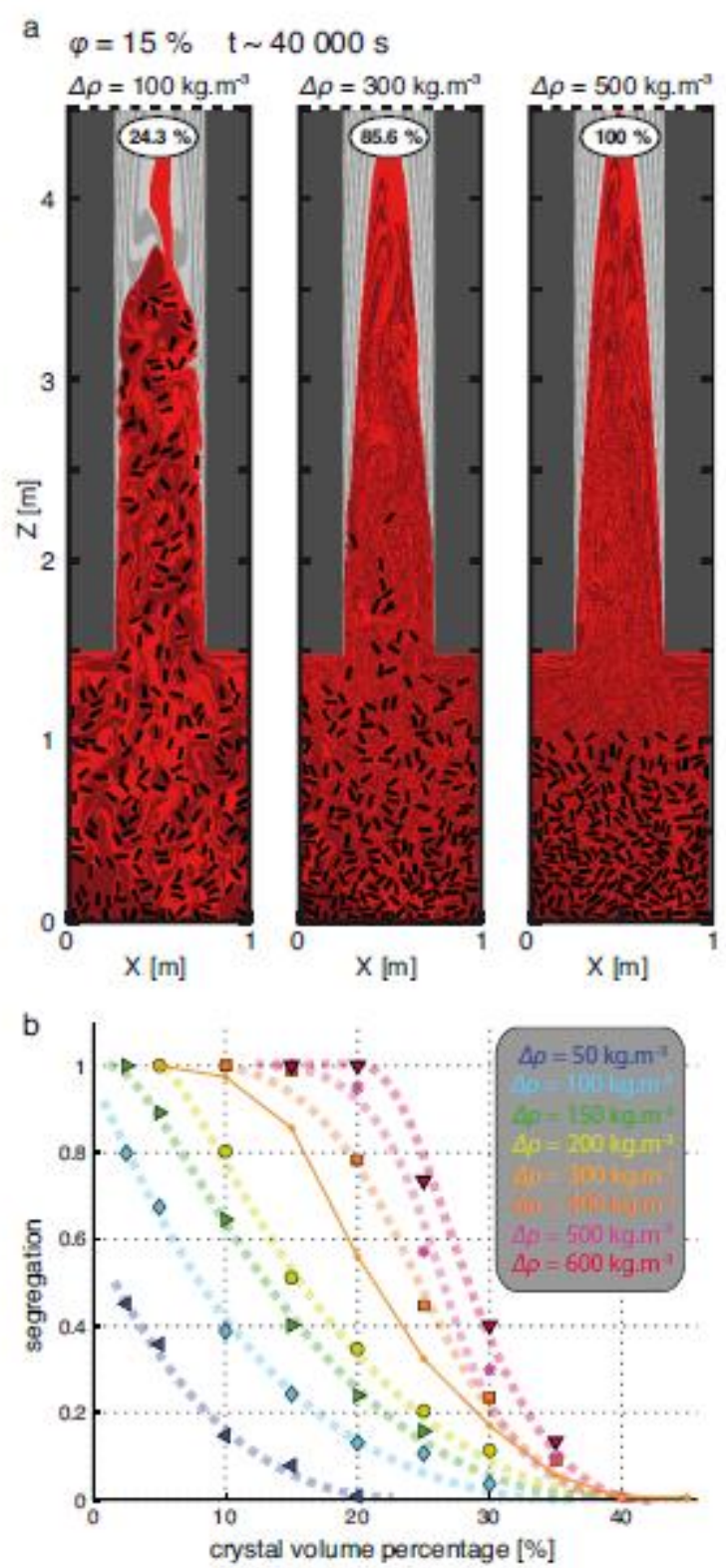

Figure 6. Influence of the crystal-melt density difference $\Delta \rho$. In these numerical experiments only the crystal density was varied, while keeping the melt density constant. (a) Results obtained after $40000 \mathrm{~s}$ for $\Delta \rho=100$, 300 , and $500 \mathrm{~kg} \cdot \mathrm{m}^{-3}$, respectively. Computed segregation values are indicated in the white ellipses for each experiment. (b) Segregation values computed as a function of the crystal volume percentage $\varphi$ for different $\Delta \rho$ values. 
Figure 7

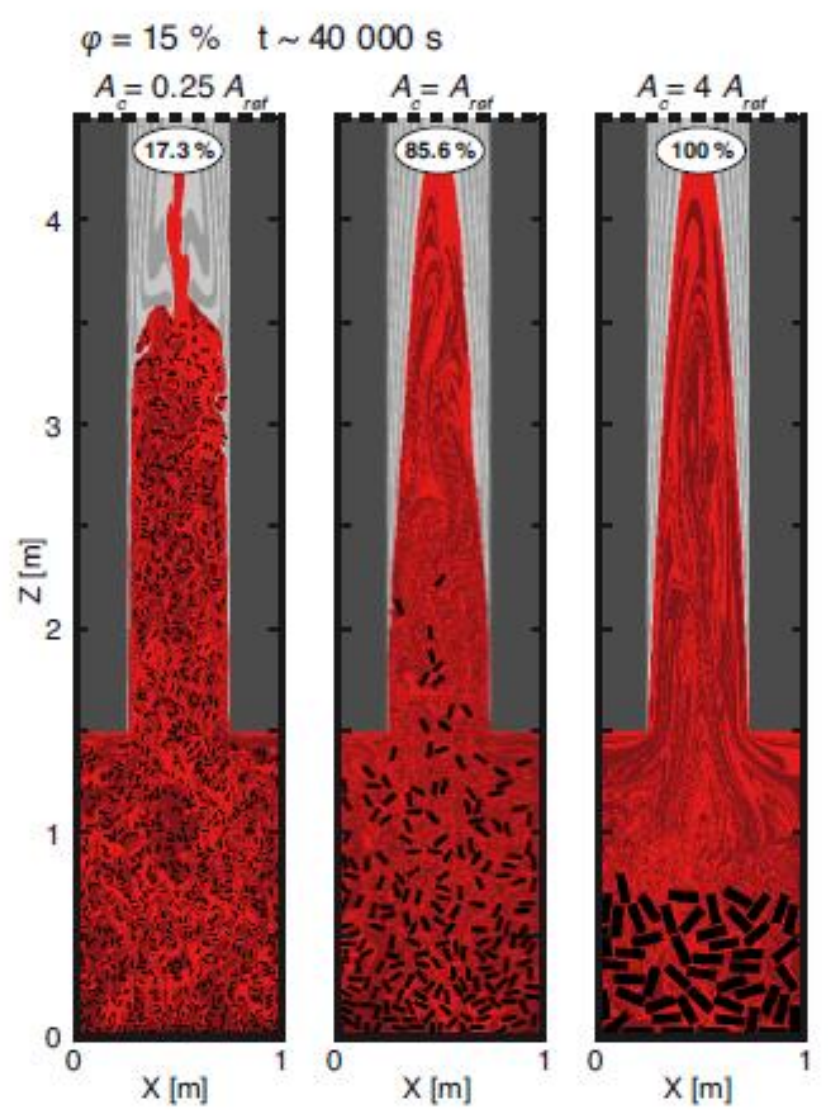

Figure 7. Influence of the crystal size. The crystal volumes $A_{c}$ were varied, while the other parameters were kept consistent with those used for the reference experiment. Results are shown here after $40000 \mathrm{~s}$ of the numerical simulation. $A_{r e f}$ corresponds to the crystal size of the reference experiment (i.e. $0.025 \times 0.075 \mathrm{~m}^{2}$ ). The crystal fraction is the same in the three experiments (i.e. the total mass of crystals is the same). The white ellipses indicate computed segregation amounts. 


\section{Figure 8}

a

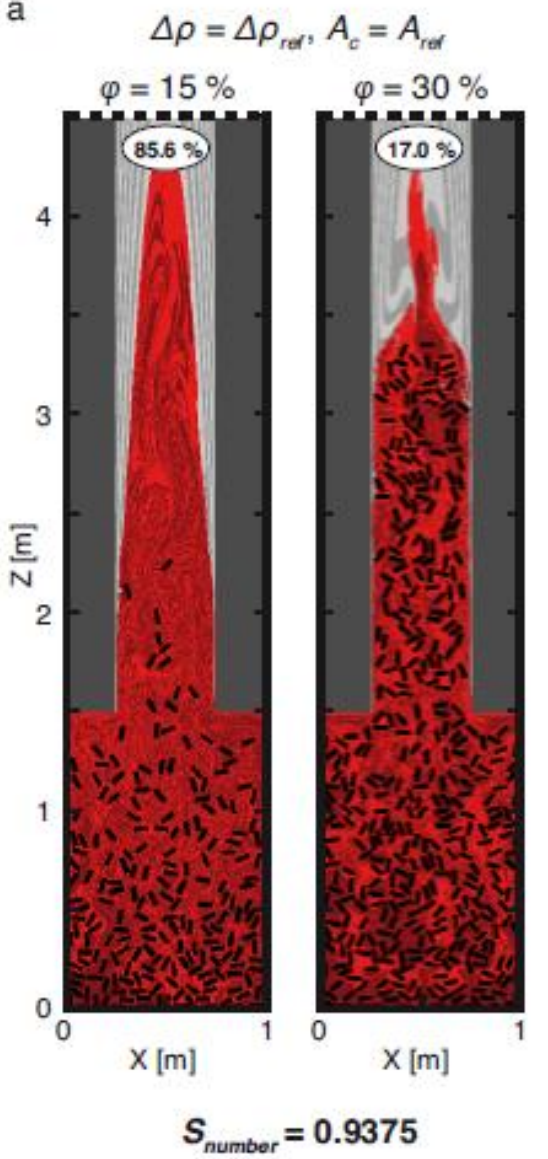

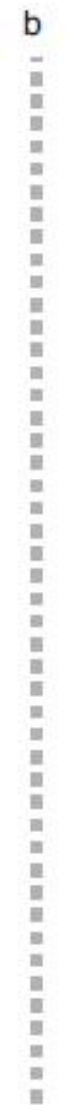

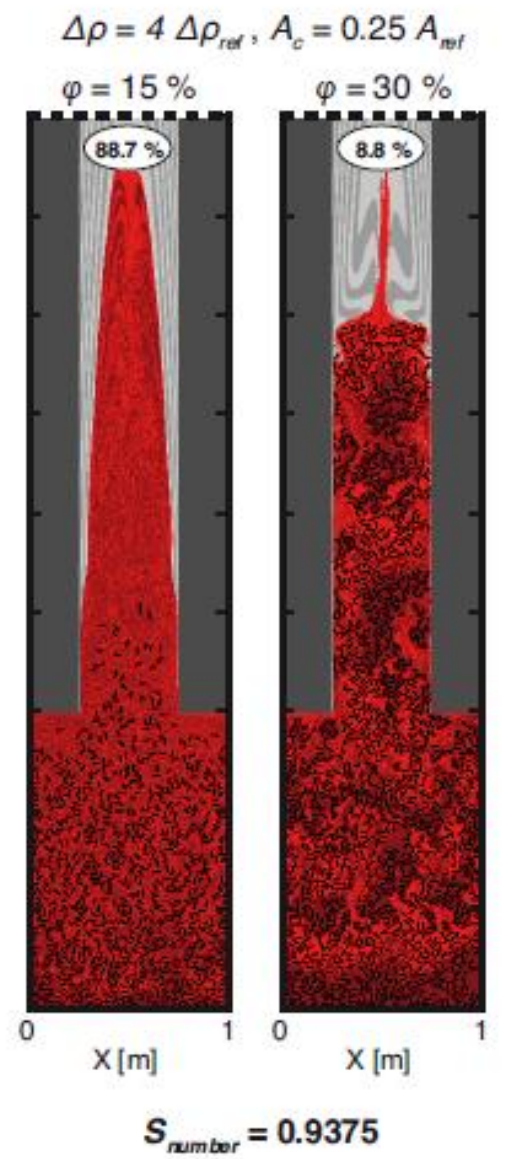

Figure 8. Model sensitivity to $S_{\text {number. }}$. Numerical experiments performed with the same $S_{\text {number }}$ (but different input parameters) exhibit the same overall behaviour. (a) Results obtained at $15 \%$ and $30 \%$ crystal volume percentage. $A_{\text {ref }}$ and $\Delta \rho_{\text {ref }}$ correspond to the crystal size (i.e. $0.025 \times 0.075 \mathrm{~m}^{2}$ ) and to the density difference between crystals and melt (i.e., $300 \mathrm{~kg} \cdot \mathrm{m}^{-3}$ ) of the reference experiment, respectively. (b) Results obtained also at $15 \%$ and $30 \%$ crystal volume percentage for different $\Delta \rho$ and $A_{c}$ but keeping $S_{\text {number }}$ constant. 
Figure 9
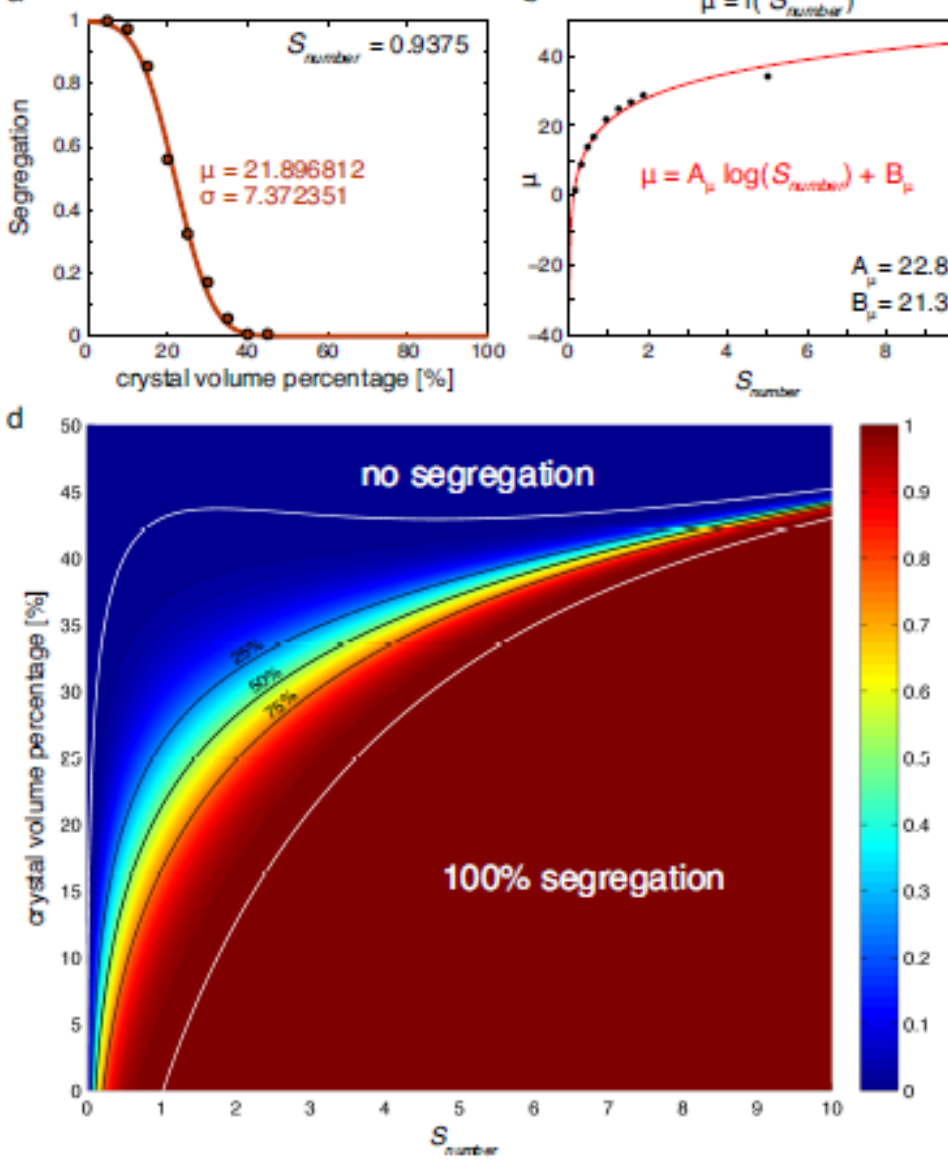

b
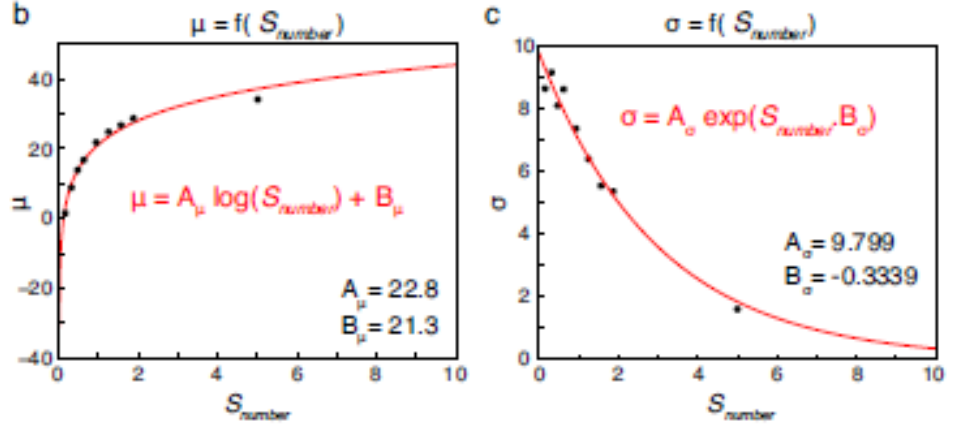

e

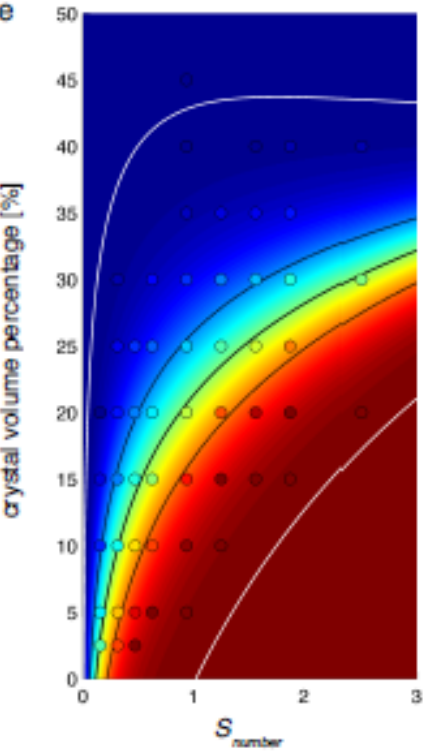

Figure 9. Prediction of the segregation amount as a function of the crystal volume percentage $(\varphi)$ and $S_{\text {number- (a) Cumulative normal distribution fit (orange line) obtained from the segregation values computed }}$ in our numerical simulations for different crystal volume percentage (dots) at a given $S_{\text {number }} \mu$ and $\sigma$ corresponds to the mean and the standard deviation of the best fits of the data points, respectively. (b) $\mu$ vs. $S_{\text {number }}$ fit. Black stars correspond to the mean values obtained (as in Fig. 9a) for different set of numerical experiments at a given $S_{\text {mumber }}$ The red line corresponds to the law (equation in red) that can be used to predict $\mu$ for any given $S_{\text {number. }}$ (c) $\sigma$ vs. $S_{\text {namber }}$ fit. Black stars correspond to the standard deviation values obtained (as in Fig. 9a) for different set of numerical experiments at a given $S_{\text {number. }}$ The red line corresponds 
to the law (equation in red) that can be used to predict $\sigma$ for any given $S_{\text {number. }}$ (d) Diagram predicting the amount of segregation (Seg*) as a function of the crystal volume percentage $(\varphi)$ and $S_{\text {number. }}$ (e) Close-up view of the Segregation prediction (Seg*) diagram for $S_{\text {number }}$ ranging between 0 and 3 . Values obtained in our numerical simulations are also indicated by colour dots. 


\section{Figure Al}
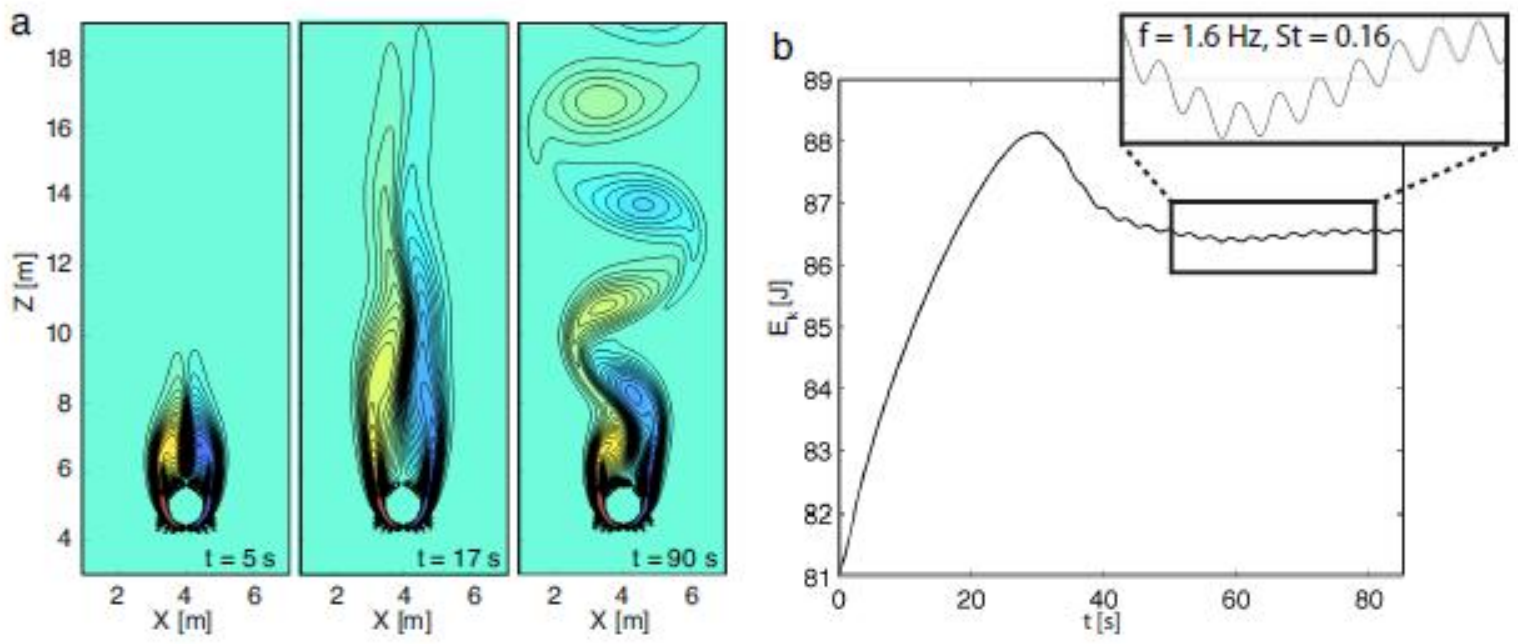

Figure Al. (a) Vortex shedding test $(R e=100)$ in a $8 \times 20 \mathrm{~m}$ box $\left(N_{x}=125, N_{2}=250\right)$. The centre of a fixed cylinder (radius $0.5 \mathrm{~m}$ ) is located at $x=4 \mathrm{~m}$ and $z=5 \mathrm{~m}$. An inflow velocity of $10 \mathrm{~m} \cdot \mathrm{s}^{-1}$ is prescribed at the bottom side, zero normal stress is applied on the upper boundary and the lateral walls are free-slip. (b) Variations of kinetic energy with time. The onset of the vortex shedding instability ( $t \sim 30 \mathrm{~s}$ ) yields to periodic fluctuations of kinetic energy $(1.6 \mathrm{~Hz})$. 
Figure A2

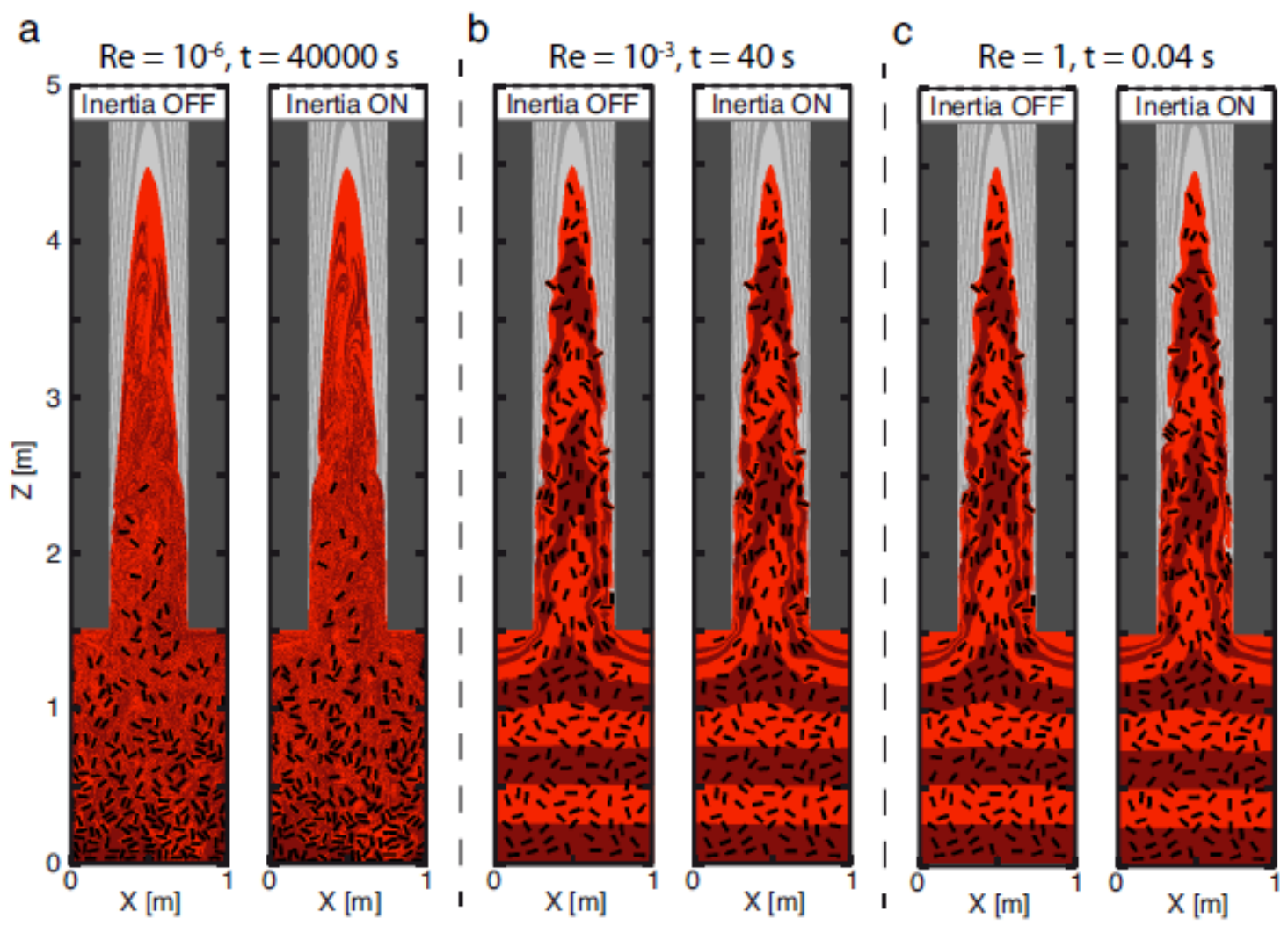

Figure A2. Difference between models with or without inertia. Other model parameters are the same than those employed in the reference model (Fig. 1). Simulations encompassing the same initial crystal arrangement were computed with and without including inertial terms. The case $R e=10^{-6}$ corresponds to the reference experiment that leads to segregation. Final crystal positions can be affected but the macroscopic behaviour is maintained. Simulations computed at higher $\operatorname{Re}\left(10^{-3}<\operatorname{Re}<1\right)$ are out of the segregation field $\left(10^{-3}>S_{\text {number }}>10^{-6}\right)$. 
Figure A3

a

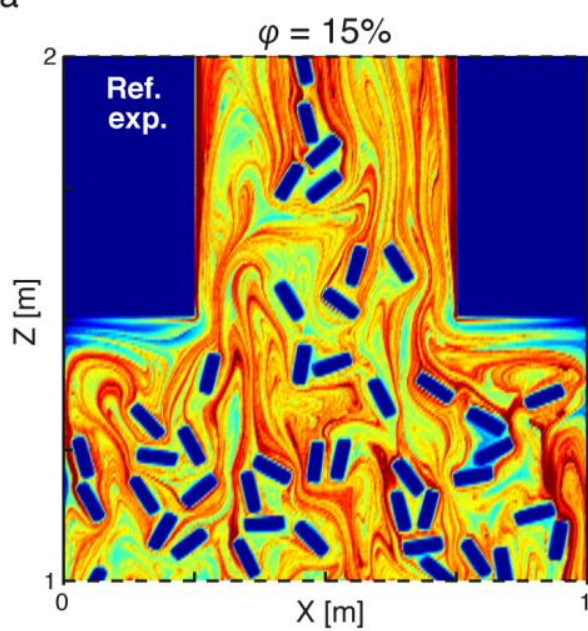

b

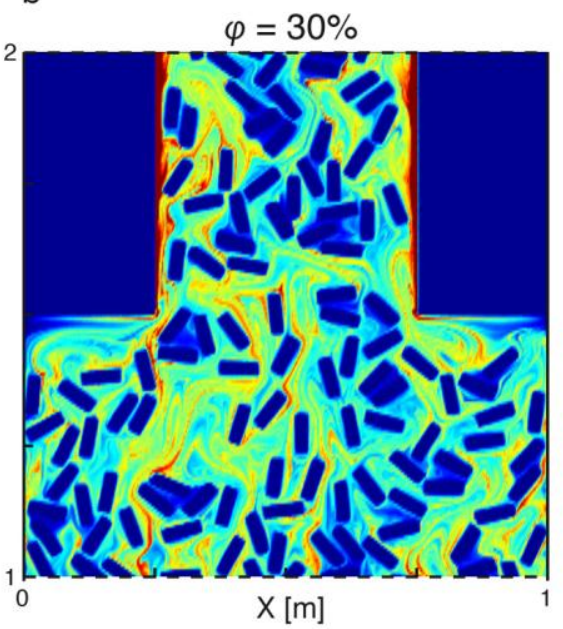

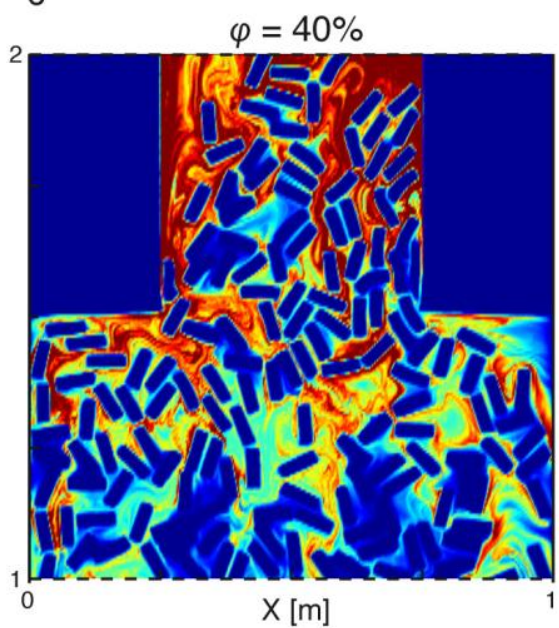

d

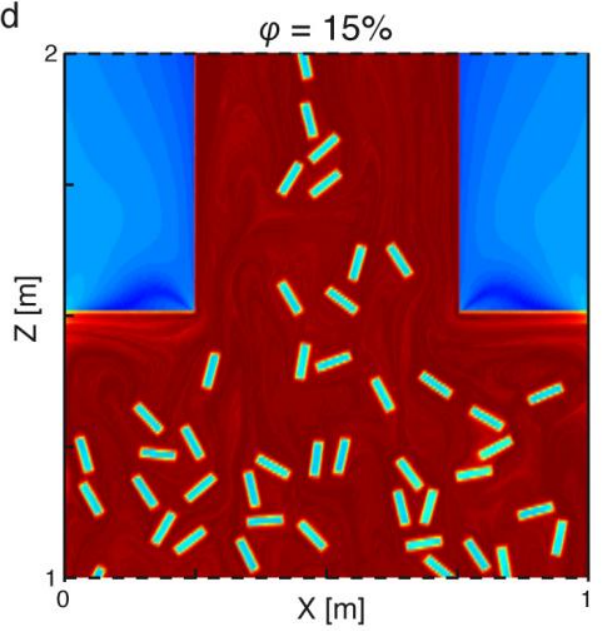

e

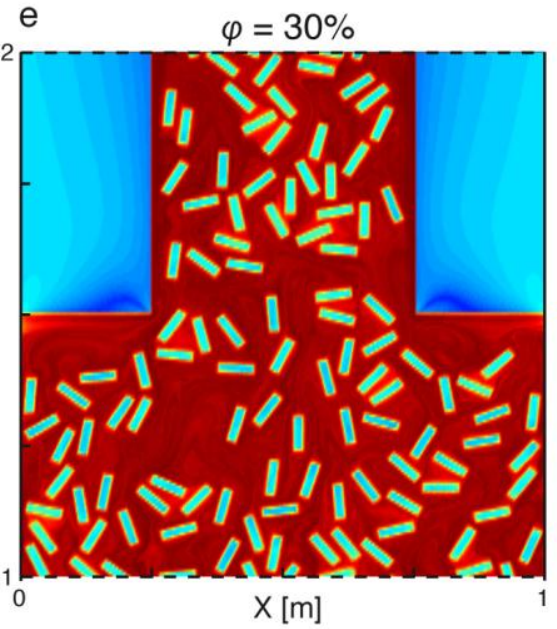

$f$

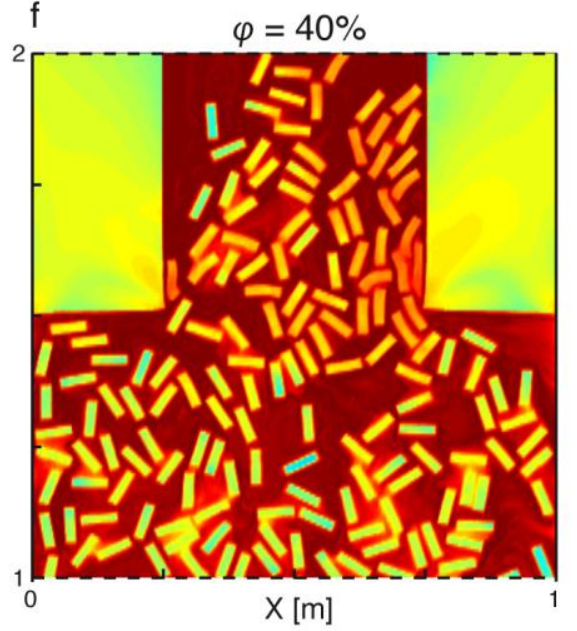

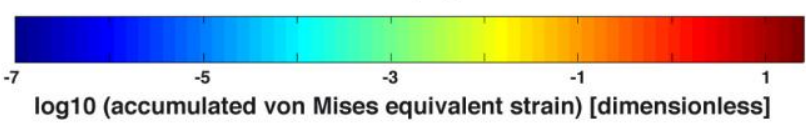

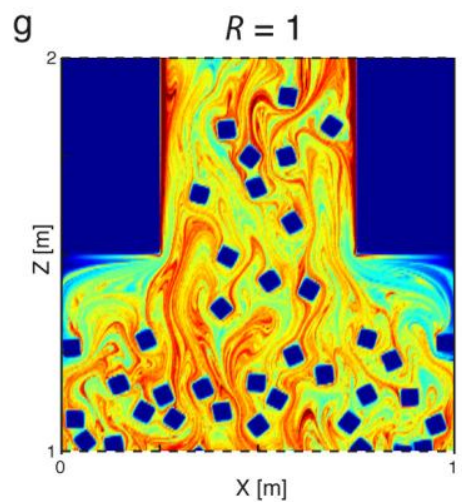

$\mathrm{h}$
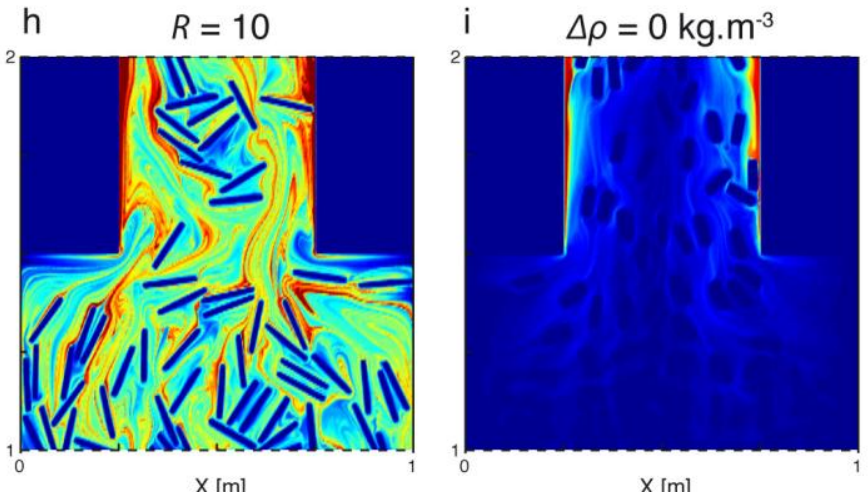

$\mathrm{X}[\mathrm{m}]$
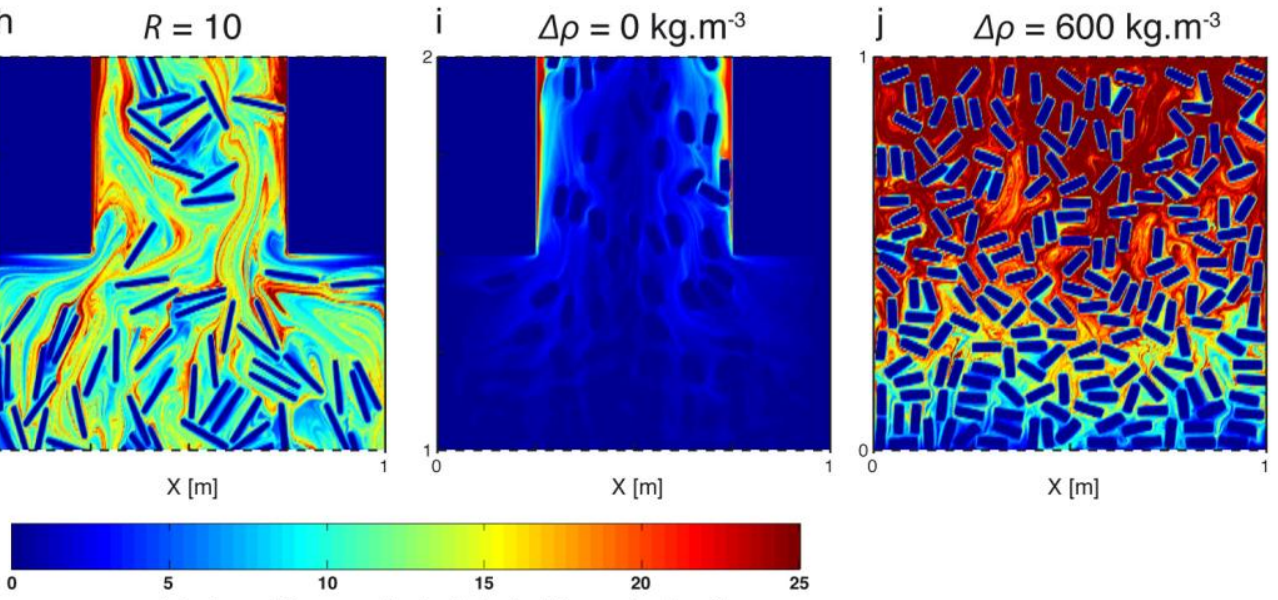

accumulated von Mises equivalent strain [dimensionless] 
Figure A3. Fluid vs. solid deformation after 40000 s of experiment. (a-c) Accumulated von Mises equivalent strain (computed as in Frehner and Schmalholz, 2006) for the reference experiment (crystal volume percentage $\varphi=15 \%$ ), $\varphi=30 \%$ and $\varphi=40 \%$, respectively. In all cases, deformation occurs within the melt and crystals remain undeformed. (d-f) $\log _{10}$ of Accumulated equivalent strain, for the same experiments, allowing to better visualise how "rigid" are the crystals in our experiments. This shows that strain magnitude in crystal is the same as for the rigid blocks of the piston and in the order of $10^{3}$ to $10^{6}$ times lower than within adjacent melt. (g-h) Accumulated von Mises equivalent strain for different crystal aspect ratios $R$, all the other parameters are as for the reference experiment. (i-j) Accumulated von Mises equivalent strain for different density differences $(\Delta \rho)$ between the crystals and the melt, all the other parameters are as for the reference experiment. This figure A3 shows that only a few runs, corresponding to extreme cases (e.g. $>45 \%$ of crystal volume percentage), show slight distortion of the crystals. However, this occurs when segregation is already impeded, and consequently, this should not strongly bias our results concerning the segregation process. 


\section{Appendix}

\section{A1 - Influence of inertia on crystal bearing magma flow}

In the numerical simulations, the Reynolds number $R e$ can be computed using the relationship:

$$
\operatorname{Re}=\frac{\rho_{m} U_{a m} W_{d}}{\eta_{m}}
$$

Considering a constant melt density $\rho_{m}\left(2400 \mathrm{~kg} \cdot \mathrm{m}^{-3}\right)$, a melt viscosity $\eta_{m}$ of $10^{4}$ Pa.s and a driving pressure of $24 \mathrm{~Pa}^{-1}$ yields a Reynolds number on the order of $10^{-6}$. In order to evaluate the impact of inertia on our results, we have extended our viscous Stokes solver to account for fluid and solid acceleration. The Navier-Stokes equations are solved implicitly (backward Euler) and the nonlinear convective acceleration term is treated by Picard iterations. The implementation was verified by running a vortex shedding experiment (e.g. Suckale et al., 2012a) with a Reynolds number of 100 (Fig. A1a). Our calculation delivers a vortex frequency of $1.6 \mathrm{~Hz}$ (Strouhal number of 0.16, Fig. A1b), which is in good agreement with other studies (Suckale et al., 2012a, and references therein). Subsequently, we have run our reference model (see Section 3.1.) while taking inertia into account (Fig. A2). The obtained results indicate that inertial effects may affect the final position of crystals travelling in the conduit. However, under such experimental conditions, inertial effects do not produce notable variations on the amount of segregation, nor on the structures that develop during magma ascent. 
Table 1

\begin{tabular}{|l|c|c|c|c|c|c|c|}
\hline System & $\rho_{m}\left(\mathrm{~kg} \mathrm{~m}^{-3}\right)$ & $\rho_{c}\left(\mathrm{~kg} \mathrm{~m}^{-3}\right)$ & $\Delta \rho\left(\mathrm{kg} \mathrm{m}^{-3}\right)$ & $A_{c}\left(\mathrm{~m}^{2}\right)$ & $\eta_{\text {am }}\left(\mathrm{Pa} \mathrm{s}^{-1}\right)$ & $U_{\text {am }}\left(\mathrm{m} \mathrm{s}^{-1}\right)$ & $S_{\text {number }}$ \\
\hline Ol-Kimberlite & 2900 & 3300 & 400 & $2.5 \times 10^{-5}$ & $10^{1}$ & 5 & $\sim 10^{-4}$ \\
\hline Cpx-Basalt & 2700 & 3400 & 700 & $2.5 \times 10^{-7}$ & $10^{2}$ & $1.5 \times 10^{-3}$ & $\sim 10^{-3}$ \\
\hline Ol-Basalt & 2700 & 3300 & 600 & $9.0 \times 10^{-6}$ & $10^{2}$ & $1.5 \times 10^{-3}$ & $\sim 5 \times 10^{-2}$ \\
\hline Fsp-Granite & 2400 & 2600 & 200 & $1.0 \times 10^{-4}$ & $10^{5}$ & $1.0 \times 10^{-6}$ & $\sim 10^{-1}$ \\
\hline
\end{tabular}

Table 1. First order estimates of $S_{\text {number }}$ values for different natural examples. Ol-Kimberlite, Cpx-

Basalt, Ol-Basalt and Fsp-Granite correspond to the segregation of olivine in a kimberlitic magma, clinopyroxene in a basaltic magma, olivine in basaltic magma and plagioclase feldspar or $\mathrm{K}$ feldspar in a leucogranitic magma, respectively (see text for details). 
- We present 2D numerical models simulating the ascent of crystal-bearing magma in dyke

- We evaluate the role of magma parameters on crystal-melt segregation

- The crystal fraction and the segregation number control the amount of segregation

- Crystal aspect ratio does not noticeably affect magma flow, hence segregation

- We provide a first order scaling law to predict crystal-melt segregation in dykes 